DOI: $10.2174 / 0929867324666170714102619$

\title{
CHEMISTRY IN THE BIOACTIVITY OF CHLOROPHYLLS: AN OVERVIEW
}

\author{
Antonio Pérez-Gálvez, Isabel Viera, and María Roca*
}

Food Phytochemistry Department, Instituto de la Grasa, Consejo Superior de Investigaciones Científicas (CSIC), University Campus Pablo de Olavide, Building 46, Carretera de Utrera km. 1, Sevilla 41013, Spain

\begin{abstract}
Background: In addition to the considerable number of different chlorophyll structures originated naturally, prominent research is made to produce new specific semi-synthetic structures. The final target is to obtain chlorophyll derivatives with even better bioactive properties than those of the natural parent compounds.

Method: A detailed, extensive and critic literature search have been made in Web of Science ${ }^{\mathrm{TM}}$

Results: Great efforts are applying to optimize the function of chlorophyll-based photosensitizers, to understand the molecular mechanisms of the antioxidant and antigenotoxic properties of chlorophyll derivatives and, lastly, to investigate new biological actions of them. However, the fundamental of the physiological functions of the chlorophylls are their physicochemical properties.

Conclusion: This review aims to reflect the chemical grounds of the healthy and/or medical features of chlorophylls, including the consequences, advantages or even new actions that modifications over the chlorophyll structure introduce. Finally, new perspectives in the functionality of chlorophylls at molecular level are discussed.
\end{abstract}

Keywords: Antigenotoxic, antimutagenic, antioxidant properties, bioactivity, chemical modifications, chlorophylls, functionality, structure. 


\section{INTRODUCTION}

Due to their essential role in photosynthesis, chlorophylls are omnipresent pigments from algae to higher plants. In addition to the components of the photosynthetic chain (chlorophyll $a$ and $b$, and pheophytin $a$ ), a number of complex chlorophyll derivatives are formed in green tissues as a consequence of the natural metabolism, or during the food storage/processing [1-2]. Taking into account the recommendation of the WHO/FAO of a minimum intake of $400 \mathrm{~g}$ fruits and vegetables per day, probably the consumption of chlorophylls could be around $200 \mathrm{mg}$ per day. Trends in nutrition such as "detox juices", or "souping" will only increase such amount. Indeed, due to this "green-food" tendency, in the recent years there has been an increase in the number of scientific reports that prove chlorophylls to exert prominent benefits to human health when consumed: antioxidant [3], antimutagenic [4], antigenotoxic [5], etc. In addition to these healthy properties, several chlorophyll derivatives are studied in relation to prevent or to treat specific illness: cancer [6], infections [7], dermatologic affections [8], etc. The structural configuration of a molecule determines its chemical mode of action, and chlorophylls are not an exception. Although great research efforts have been done in relation to the chemistry of the chlorophylls [9-10], only a few of them reflect the relation structure-function [11-12]. The purpose of this review is not only to make an updated overview of the functional properties of chlorophylls, but to relate the healthy properties of the chlorophyll derivatives with the different chemical structures of each compound.

\section{Structures of chlorophylls}

Chlorophylls are one type of tetrapyrrole compounds with a system of coplanar conjugated double bonds that forms an aromatic structure with delocalization of electron density in $\pi$ orbitals. Therefore, chlorophylls are defined as cyclic tetrapyrroles that carry a characteristic isocyclic five-membered ring and are functional pigments in light-harvesting or in charge separation in photosynthesis [13]. There are naturally occurring more than 100 different structures of chlorophylls, although most of them appear only in the green bacteria. For the present review, only those chlorophylls related with the aim of the study are described. Fig. (1) shows the structure of chlorophyll showing the IUPAC-IUB numbering system for chlorophylls. The structure carries one magnesium atom as the central metal and a phytyl chain $\left(\mathrm{C}_{20} \mathrm{H}_{40}\right)$ esterifying the 
propionic acid at $\mathrm{C} 17$. However, there are exceptions for both characteristic arrangements as it will be shown later.

At present, five different chlorophyll structures are accepted (Fig. 2) that show two different macrocycle types. Porphyrins are completely unsaturated and exhibit an intense absorption in the blue region and a moderate absorption around $620 \mathrm{~nm}$. Porphyrins are the basic structure of chlorophylls $c\left(c_{1}, c_{2}\right.$ and $\left.c_{3}\right)$, which usually are non-esterified with phytol at $\mathrm{C} 17$, and consequently they are chlorophyllides in a structural basis. The second type of macrocycle are the chlorins defined as 17,18dihydroporphyrins, which conform the structure of chlorophyll $a, b, d$ and $f$. Chlorins compounds typically absorb around $440 \mathrm{~nm}$ and $660 \mathrm{~nm}$.

Chlorophyll $a$ (1, Fig. 2) carries a typical methyl group at C7 meanwhile chlorophyll $b$ (2, Fig. 2) and its derivatives contain a formyl group at C7. Chlorophyll $d$ (3, Fig. 2) exhibits a formyl group at $\mathrm{C} 3$, in contrast with the typical vinyl group present in the rest of chlorophyll derivatives. Chlorophylls $c$ mostly contain an acrylic acid side chain at $\mathrm{C} 17$, chlorophyll $c_{1}$ (4, Fig. 2) presents a characteristic ethyl group at C8 and chlorophyll $c_{2}$ a vinyl group at C8 (5, Fig. 2).

Independently of the chlorophyll series ( $a, b, c, d$ or $f$ ), chlorophylls experiment chemical or enzymatic modifications in their natural physiological ambient due to metabolic pathways. Two main reactions affect the structure of chlorophylls. The first reaction is the substitution of the central magnesium atom of the tetrapyrrole by two hydrogen atoms [14]. This reaction occurs easily under acid conditions or due to a metal chelating substance (some authors refer to $\mathrm{Mg}$-dechelatase or protein releasing magnesium [15-16]. If this reaction proceeds on chlorophylls the pheophytins (6, Fig. 3) are yield, but if the substrate is chlorophyllide then pheophorbides are formed (7, Fig. 3). The second important reaction is the hydrolysis of the phytol chain, which takes place under enzymatic (chlorophyllase and/or pheophytinase) [17] or alkali conditions. Chlorophyllides (8, Fig. 3) are produced if the reaction starts with chlorophyll, and the process yields pheophorbides (7, Fig. 3) if the dephytylation starts from pheophytin.

Chlorophyll compounds are relatively unstable and prone to oxidations, as the substitution of the hydrogen atom at $\mathrm{C}_{13}{ }^{2}$ by a hydroxyl group, forming the $13^{2}$ hydroxy derivatives (9, Fig. 3), either chemically or enzymatically [18]. A further oxidation implies the rearrangement of the isocyclic ring (ring E, Fig. 1), producing the lactone group, and the $15^{1}$-hydroxy-lactone derivatives (10, Fig. 3). A different modification that also involves ring $\mathrm{E}$ is the formation of the purpurin-18 derivatives 
(11, Fig. 3) [19]. Finally, the loss of the carboxymethoxy group at $\mathrm{C} 13^{2}$ yields the corresponding pyroderivatives (12, Fig. 3).

'Chlorophyllins' is a broad term to denote concentrates isolated from chemical modification of green vegetal tissues that include a wide range of water soluble chlorophyll derivatives, commonly without phytol and with the ring E opened. There is not a complete characterization of this mixture, although probably the main components are chlorin $e_{6}\left(\mathbf{1 3}\right.$, Fig. 4) and rhodin $g_{7}(\mathbf{1 4}$, Fig. 4) [20]. The semi-synthetic origin of chlorophyllins is the alkaline hydrolization (saponification) of chlorophylls extracted from grass, lucerne, or nettles. While FDA does not approve chlorophyllins neither as food additive, nor as drug [21], the EU the use of chlorophyllins with the colorant number E 140 ii [22]. Anyhow, the European Food and Safety Authority (EFSA) is reevaluating all the allowed food additives, particularly the E 140 ii [23], and concludes so far that it is not possible to assess the safety of chloropyllins (E 140(ii)) as food additives due to the scarce data available.

The treatment of chlorophyllins with sodium copper salts originates the wellknown colorant sodium copper chlorophyllins (SCC) This mixture is water soluble and is highly stable due to the presence of copper. Although several papers have dealt with its composition [24-27], once again the complete characterization is unavailable. The main chlorophyll derivatives identified in $\mathrm{SCC}$ salts are: $\mathrm{Cu}$-chlorin $e_{6}(\mathbf{1 5}, \mathrm{Fig} . \mathbf{5}), \mathrm{Cu}-$ chlorin $e_{4}$ (16, Fig. 5), Cu-isochlorin $e_{4}\left(\mathbf{1 7}\right.$, Fig. 5), Cu-chlorin $p_{6}(\mathbf{1 8}$, Fig. 5) and, in minor amounts and depending of the identification grade: $\mathrm{Cu}$-rhodin $g_{7}$ (19, Fig. 5), Cupurpurin 7 (20, Fig. 5) or Cu-rhodochlorin (21, Fig. 5). FDA approves the use of SCC salts on foods only to provide color in citrus-based dry beverage mixes, in amounts not exceeding $0.2 \%$ in the dry mix, and in dentifrices at $0.1 \%$ [21]. By contrast, the EU allows the use of SCC salts as food additive with the reference number E 141ii [22]. After the recent review of the EFSA [28] regarding this colorant, the expert panel concluded that the available data should be considered inadequate and that the specifications of E 141ii should be updated to include detailed information about identification of all its components.

\section{Structure-activity relationship}

Physicochemical properties are the starting point for acknowledgment of potential activities of a compound, which may be measured or calculated with in silico platforms. The latter procedure has many advantages, including the speed and low cost of calculation, it is mandatory when the component is unstable under the experimental 
conditions for measurement of the property, and even it could be performed with compounds still not available. This possibility is very valuable in the chemical design of a compound for a specific target or function, or when structural re-arrangement of a parent component is necessary. Several physicochemical properties and molecular descriptors will cause the fate of the compound in an environment, its chemical mode of action, and the biological activity resulting in the final outcome that might be beneficial or not. Therefore, it is useful to identify the main structural determinants of the compound that drive the structure-activity relationship in each property profile.

Versatility is the right word to express the wide range of functions that chlorophylls are able to perform in the photosynthetic reaction centers, their natural environment, collecting and funneling light, as electron carriers, and several other cooperative effects [29-30]. This versatility is an expression of the characteristic molecular arrangements of chlorophylls, particularly their $\pi$-electron system through which interactions with vicinal molecules are orchestrated by electrostatic, van der Waals, and other nuanced chemical exchanges of different functional groups. Once out of their natural environment, chlorophylls still keep this versatility, considering the wide range of biological activities they may develop, which have been detailed in later sections. Indeed, the same key properties identified as significant factors for their function in photosynthesis are their main structural determinants that shape properties like solubility/aggregation [31-32] and affinity to protein transporters [5, 33], which effect route of administration, tissue permeability, bioavailability and pharmacokinetic parameters, UV-visible light absorption properties [34], which constraint the therapeutic window in photodynamic therapy (PDT), and electron/hydrogen transfer ability [35], which impel chemical modes of action, interactions with reactants and chemical stability. Additionally, there are several options for chemically refit either the basic cyclic tetrapyrrole unit or the side chains, which may allow or enhance a specific process or activity, as it will be discuss in later sections.

Accordingly, the central magnesium metal ion and the phytyl chain are two features that primarily state chemistry of chlorophylls as they are frequent units associated to the tetrapyrrole system [36]. Mg ion performs coordination center activity, and readily accepts axial ligands making the binding of the pigment to proteins very easy [10]. Its presence does not modify the charge density distribution of the $\pi$-electron system, causing no heavy atom effects on the chlorophyll, and it is easily released in acidic environments [37]. The substitution of $\mathrm{Mg}$ ion by other central metal strongly 
changes these characteristics. Thus, inclusion of copper or zinc modifies the coordination center activity, and the binding of the pigment to proteins is shifted [38]. This is crucial for the aggregative properties of the molecule to xenobiotics, one of the accepted mechanisms of action of chlorophylls. Charge density distribution is also amended and, consequently, the kinetics of those processes where electrons switch and redox potential play a key role are modified. But the most important facets that substitution of central $\mathrm{Mg}$ ion transforms are related with pigment stability and kinetics of diffusion/transport through tissues. First, coordination of the tetrapyrrole system with metals different than $\mathrm{Mg}$ increases the stability of the molecule making the pigment metabolism or degradative pathways, when necessary, more difficult to occur [39]. Thus, catabolism by intestinal microflora of metal-pheophytins is significantly decreased in comparison with that of chlorophyll [12]. In the same way, metalpheophytins are less prone to enzymatic breakdown increasing the deposition ranges in tissues [40-41]. Indeed, where a protein system is associated to pigment transport by epithelial tissues, either for absorption and efflux, the change of $\mathrm{Mg}$ by $\mathrm{Zn}$ adjusts the trafficking of the molecule what correlates well with substrate specificity of the protein(s) involved in the pigment transport [12].

In regard to the phytyl chain, this residue is not involved in the $\pi$-electron system configuration of the tetrapyrrole macrocycle and its influence in the intermolecular interaction of chlorophylls is related to the increment on hydrophobicity of the molecule, when the phytyl chain is present, and thereof the enhancement of the aggregative properties this residue makes [30]. However, phytyl chain removal from the chlorophyll structure develops a relief of the overall steric hindrance of chlorophyll allowing interactions with ligands that were previously avoided [42]. As a collateral effect, the unesterified propionic residue performs an intramolecular chelation outcome, increasing the stability of the central $\mathrm{Mg}$ ion [43]. Consequently, influences of phytyl chain on the chlorophyll pigment encompass not only hydrophobicity and steric hindrance of vicinal functional groups but also the capacity of the macrocycle to join ligands, and the stability of the chlorophyll structural conformation.

Although central metal ion type and presence/absence of the phytyl chain perform the significant influences on the chemical activity or interactions of chlorophyll pigments with the environment, effects of the additional structural residues on the modes of action deserve attention. Indeed, they offer further opportunities for tuning the structural pigment qualities to enhance those characteristics not fully attained with 
modification of the former main structural determinants. Thus, we should consider the peripheral substituents and the isocyclic ring as alternate arrangements in the structureactivity relationship. Among the peripheral substituents, the auxochromes, carbonyl groups at $\mathrm{C}^{1}{ }^{1}$ position, at $\mathrm{C} 7$ in chlorophyll $b$ (Fig. $\mathbf{2}$ and 3 ) and in bacteriochlorophylls contribute in some extent to the $\pi$-electron system properties by changing absorption properties as they are directly linked to the chromophore system. In a similar fashion, modifications at the $\mathrm{C} 3$ position also contribute to adjustment of the excited singlet-state energy and that state lifetime. For instance, the inclusion of alkoxy groups with different chain length starting from pheophorbide $a$ (7, Fig. 3) enhances the stability and increases the hydrophobicity with regard to the parent compound what results in advantageous properties for PDT activity [44-45], as it will explained later.

Last but not least, the isocyclic ring is another structural determinant in chlorophyll pigments properties that may result in a different chemical/biological behavior. This structure is particularly prone as it has been explained before to chemical modifications like hydroxylation and decarbometoxylation at $\mathrm{C}_{13}{ }^{2}$, yielding hydroxy and pyro derivatives (9 and 12, Fig. 3), or inclusion of electron-attracting group(s) at $\mathrm{C} 15^{1}$, yielding lactone and purpurin derivatives (10 and 11, Fig. 3). Even ring-opening reactions are likely to produce other chlorophyll derivatives (chlorins, 13, Fig. 4). Among this array of chemical modifications, those yielding purpurin (11, Fig. 3) and chlorin derivatives are the most outstanding processes as they do significantly contribute to a different performance of the chemical action mode of the chlorophyll structure. Purpurins (11, Fig. 3) contain a 6-membered anhydride ring arising from the oxidative cleavage of the isocyclic ring and the subsequent chemical modifications at that cyclic unit offer interesting enhanced properties. Additional structures with $\mathrm{N}$ substituted residues present an increased hydrophilicity and extend the wavelength absorption to $700-800 \mathrm{~nm}$. Indeed, inclusion of fluorinated analogs is reasonable where the alkyl chains have been replaced by fluorinated functionalities that enhance the in vivo efficacy [46]. Purpurins are also a good starting point for the synthesis of active dimeric or oligomeric components for PDT. The additional chain residue to the anhydride ring is used to covalently link the chlorophyll derivatives, expanding the photophysical properties that make favorable their use in PDT [47], as it will be reviewed later. Chlorins (13, Fig. 4) are characterized by the chain structures that arise from the lysis of the isocyclic ring, which are the center for chemical modifications that improve the solubility and/or biological activity. Thus, these derivatives present a 
higher hydrophilicity and can be attached to aminoacids that perform carrier action through the desired target tissue [11].

\section{Bioactivity of chlorophylls}

\subsection{Antioxidant activity}

Human organism is exposed to a variety of different prooxidant compounds able to damage biologically relevant molecules, such as DNA, proteins, carbohydrates, and lipids [48-49]. Consequently, the ingestion of foods with intrinsic antioxidant properties is very important as they contribute to sustain continuously the antioxidant system of the organism. Several contributions support the antioxidant properties of chlorophylls pigments and, recently, several reviews have summarized the main results and impacts of such properties [3, 50]. Significant antioxidant activity towards radical oxygen species generated by radiation or chemically induced by oxidative stress have been the subject of intensive research [51-52]. Thus, regarding the antioxidant activity against oxidative stress or reactive oxygen species (ROS) generated during exposition to radiation sources, Zimmering et al. [53] reported the first evidences. The authors showed that the SCC complexes $(\mathbf{1 5 - 2 1}$, Fig. 5) behave radio protective activity by means of mutation and recombination tests in somatic Drosophila melanogaster cells. They found that concentrations of SCC reduced significantly the frequency of mutations induced by gamma radiation in the cells. In this study, authors suggest that the mechanism of action of the SCC is capture of free radicals and their subsequent deactivation. Pimentel et al. [54] demonstrated that the radio protective effect in the same somatic cells continued for 72 hours after administration of radiation. Later, Kummar et al. [55] investigated the antioxidant effects of chlorophyllin towards different ROS by means of electron spin resonance spectroscopy (ESR). The $\mathrm{OH}$ radicals were generated by different methods: exposure to $\Upsilon$-radiation as well as by Fenton reaction, $\mathrm{O}_{2}$ by photosensitization using methylene blue (MB) as a sensitizer, and finally by hydrogen peroxide. Spin-trapping in combination with ESR spectroscopy clearly demonstrate a scavenging effect towards the physiologically relevant $\mathrm{OH}$ and $\mathrm{O}_{2}$ radicals, and the standard DPPH radical. Chlorophyllin inhibited generation of DMPO (5-5- dimethyl-1-pirroline-N-oxide)-OH adduct by irradiation, as well as by Fenton reaction. However, concentrations required to inhibit the DMPO-OH adduct were higher in case of exposure to $\Upsilon$-radiation in comparison with the Fenton reaction source. The authors concluded that SCC protected from damage caused by radiation with different origins and that the antioxidant effect is concentration-dependent. 
SCC salts (15-21, Fig. 5) have shown also to be effective against the oxidative stress produced by chemicals. Sato et al. [56] investigated the antioxidant activity of SCC salts in rat liver cells and found a complete inhibition of reactive substances produced by thiobarbituric acid, delaying lipid peroxidation. Similarly, SCC salts perform effective activity against oxidative damage caused by blue methylene and ascorbate- $\mathrm{Fe}^{+2}$ and NADPH-ADP-Fe ${ }^{+3}$, decreasing the formation of lipid hydroperoxides and avoiding activation of superoxide dismutase (SOD), even more effectively than other antioxidants, such as ascorbate, mannitol and glutathione (GSH). The SCC salts can perform their antioxidant capacity by means of trapping mechanism, that is, inactivating the 2,2-diphenyl-hydrazine radicals products generated in Fenton reaction [55].

Once Egner et al. [57] proved that commercial SCC salts are absorbed and transported in humans' sera; the in vivo studies concerning antioxidant activity of SCC salts waken interest. The two main components of SCC salts are $\mathrm{Cu}$-chlorin $e_{6}(\mathbf{1 5}$, Fig. 5) and $\mathrm{Cu}$-chlorin $e_{4}$ (16, Fig. 5), but they behave different in the digestive tract, so that only $\mathrm{Cu}$-chlorin $e_{4}$ is found in serum, liver and kidneys of rats [58] or in humans' sera [57]. The study of Gomes et al. [58] evaluated the effects on the antioxidant defense system of liver and brain of rats of the absorbed chlorophyllin. The results show that presence of chlorin protected brain lipids against peroxidation observed under vitamin $\mathrm{E}$ deficiency. However the chlorin was not able to counteract the hepatic oxidative stress arising by the nutritional deficiency of vitamin E, so any antioxidant activity could be confirmed in liver. The decrease in TBARS (thiobarbituric acid reactive substances) content in brain observed in this study implies the absorption and bioavailability of chlorin in that tissue. Indeed, the fact that the protective effect of chlorin was observed only in the brain opens up the possibility that chlorin is effectively absorbed, crossing the haematoencephalic barrier, and accumulates selectively in this organ. On the other hand, the authors also studied the effect of chlorophyllins supplementation on the status of several antioxidant enzymes (GSH-peroxidase, GSH-reductase, SOD) in hepatic and brain tissues of rats subjected to oxidative stress induced by vitamin E deficiency. The activities of the enzymes are notably higher in hepatic tissue than in brain tissue, but there are any significant differences in enzymes activity among the control, vitamin $\mathrm{E}$ deficient and chlorophyllins supplemented groups. Thus, these results indicate that supplementation with chlorophyllins may interact directly with ROS in vivo but they do not interfere with the antioxidant enzymes activity. In addition, SCC salts have shown a 
relevant lipid antioxidant activity in vivo. Thus, a protective effect of SCC salts administration towards microsomal lipid peroxidation of mitochondrial liver has been demonstrated [59]. Even, SCC salts are able to protect mitochondrial tissue towards oxidative damage induced by several ROS [52].

Besides the research performed with commercial SCC complexes, the antioxidant properties of natural chlorophylls have also drawn attention. Some studies have shown that chlorophyll and pheophytin (1 and 6, Fig. 3) behave as lipid antioxidants in stored edible oils [60] and reduce free radicals activity in standard assays [51]. Even the effects are similar than those of classical antioxidants like carotenoids, vitamin E, and vitamin C [61]. Recently the research has been directed to demonstrate that antioxidant activity of natural chlorophyll derivatives is significantly reducing the impact of some diseases related to oxidative processes, such as inflammation [62-63], to prevent oxidative DNA damage [64], and to lessen risk of cancer [6]. Thus, chlorophyll and its derivative, pheophytin, have anti-inflammatory effects, which caused in vitro dose-dependent reductions in bacterial lipopolysaccharide-induced TNF-a expression, and inflammatory response of carrageenan-induced paw edema in mice, as well as in formalin-induced paw edema in rats [63]. Chlorophylls and pheophytins act as antioxidants to prevent oxidative DNA damage and lipid peroxidation both by chelating reactive ions and by scavenging free radicals [64]. Particularly pheophorbide (7, Fig. 3) may reduce metal-induced hydroxyl radical generation, thus protecting DNA from oxidative damage [65] as this derivative does not present a metal in the cyclic tetrapyrrole unit, unlike chlorophylllide and chlorophyllins (8, 13-14, Fig. 3 and 4). Consequently, it is possible that pheophorbide exerts its antioxidative capacity not only by the porphyrin stabilization of ROS, but also by their inherent ion-chelation capacity. To check this possibility, Hsu et al. [63] analyzed of the role of chlorophyll derivatives on the protection of lymphocytes against oxidative DNA damage by $\mathrm{H}_{2} \mathrm{O}_{2}$ and explored whether they can act as direct scavengers of free radicals, or as chelators of $\mathrm{Fe}^{+2}$. The authors show that chlorophyll derivatives act as antioxidants to prevent oxidative DNA damage and lipid peroxidation by both mechanisms.

One of the most prominent features of pheophorbide (7, Fig. 3) is its role as a potent antitumor and anti-glycation component by means of an antioxidant mechanism. Marine seaweeds, which are abundant, easily cultivated, and valuable food natural resources, have been reported to perform antioxidant properties and to confer beneficial health effects during inflammation, cancer, and diabetes mellitus [66]. It has been 
demonstrated that during hyperglycemia, ROS derived from advanced glycation end products may play a key role in inflammation of the endothelium, leading to the complications observed in diabetes. The isolated pheophorbide $a$ from the green algae Capsosiphon fulvenscens, grown in abundant quantities along the southwest coast of Korea and along the coasts of European North America, showed scavenging activity of the intracellular reactive oxygen species as well as monocyte adhesiveness inhibitory activity on the human myelomonocytic cell line (THP-1) and human umbilical vein endothelial cells co-cultivation system. Pheophorbide $a$ inhibits the advanced glycation end products and prevents endothelial inflammation [67]. Pheophorbide $a$ isolated from terrestrial sources like Scutellaria barbata has been shown to induce apoptosis in Hep3B cells, a virus-induced hepatoma cell line [68]. Scutellaria barbata has long been used as a Chinese medicine for the treatment of liver diseases such as hepatitis and hepatocellular carcinoma.

\subsection{Antimutagenic/Antigenotoxic activity}

The term chemoprevention and the definition of this concept were first proposed in the early 70s. Chemoprevention is defined as the use of natural or synthetic compounds to inhibit, suppress or reverse the development and progression of cancer. The continuous exposure of human population to mutagenic, carcinogenic and toxic environmental agents has led to intense research on natural plant products that reduce the harmful effects [69-70]. Since epidemiological studies have demonstrated that yellow-green vegetables are implicated in protection against cancer, it is important to explore the antimutagenic/antigenotoxic properties of natural chlorophylls. Thus, cancer preventive effects of chlorophyll and its derivatives have been extensively studied, with particular emphasis on their in vitro antimutagenic effect against numerous dietary and environmental mutagens [6].

Chlorophyll pigments have been shown to be responsible for most of the antimutagenic activity of certain vegetable extracts [71-75]. Most of the studies have been performed with commercial SCC salts (Fig. 5), which inhibit mutagenic activity of several known mutagens, including meat extract, heterocyclic amines and products arising from pyrolysis of amino acid [69, 71-73,76-84]. In a study using the Ames test [85] in Salmonella typhimurium, the authors found that the SCC salts are effective in reducing damage caused by chemicals and complex mixtures, such as aflatoxin B, 2aminoanthracene, benzo[ $\alpha]$ pyrene, N-methyl-N'-nitro-N-nitrosoguanidine and solvent 
extracts of coal dust, diesel emission particles, airborne particles, tobacco snuff, black pepper and red wine [86]. Few reports have addressed the antimutagenic properties of chlorophyll $b$ (2, Fig. 2) and the metallo-derived lipophilic chlorophylls (retaining the phytyl chain) including $\mathrm{Zn}$ and $\mathrm{Cu}$-pheophytins (22-23, Fig. 6). However, in those comparative studies the results show that dietary chlorophyll derivatives prevalent in both fresh and processed foods as well as in dietary supplements perform antimutagenic activities, and that phytyl derivatives are similarly effective as SCC salts [4]. Moreover, independently of the applied assay, all chlorophyll derivatives exhibited strong dosedependent antimutagenic activity.

One of the accepted mechanisms to explain the chemopreventive activities of natural chlorophylls or SCC salts is based on the complex formation 'chlorophyll/SCCmutagen', which it is believed to be stabilized by interactions between the cyclic tetrapyrrole unit of the chlorophyll/SCC molecule and the aromatic rings of the mutagen [87-93]. The building of that complex facilitates the degradation of the mutagen, preventing its migration and coupling to DNA [90, 94-95]. Some other mechanisms have been suggested for the inhibitory activity of chlorophylls and SCC salts including trapping of the mutagen by complex formation resulting in an accelerated passage of the mutagen through the digestive tract, and disturbance of metabolic activation of the mutagen inside the body, either through enzyme inhibition or through degradation of activated species of the mutagen $[70,96]$.

Concerning the in vivo anticarcinogenic effects of chlorophyll derivatives, numerous studies in a variety of experimental animal models and in humans have revealed that these pigments influence multiple molecules and pathways involved in the metabolism of carcinogens, cancer initiation and progression, exerting chemopreventive effects. Thus, there is a significant reduction of tumorigenesis in the stomach and liver of the rainbow trout induced by polycyclic aromatic compounds (DBC) with a highly potent carcinogenic power [97], by means of a diet rich in chlorophylls [98]. Natural chlorophyll performs a greater inhibition in the heme-induced luminal cytotoxicity and colonic hyperproliferation, during high intake of red meat [99]. The in vivo effect is due to the interaction of heme-containing substances with chlorophyll resulting in a hydrophobic complex similar to the one described by Dashwood et al. [79]. It is important to note that this effect is not attained by the SCC salts derivatives (Fig. 5). These pigments are not able to interact with the heme-containing substances as both remain negatively charged under physiological conditions avoiding the generation of 
the complex. Chlorophyll $b$ (2, Fig. 2) is related to the chemopreventive effects towards the side-effects of cistaplin (cDDP) a drug commonly used in the treatment of hematological tumors. Possible antigenotoxic effects of chlorophyll $b$ against DNA damage induced by cDDP in kidneys, liver and peripheral blood cells from mice, were observed by using electrophoresis tests [100]. These studies suggest that natural chlorophyll and its derivatives have potential capacities in the development of anticancer strategies both in the pharmaceutical and in the food industries.

There have been extensive studies on the chemopreventive effects of chlorophyll derivatives in humans. SCC salts (Fig. 5) inhibit cancer initiation and progression by targeting multiple molecules and pathways involved in the metabolism of carcinogens, cell cycle progression, apoptosis evasion, invasion, and angiogenesis [101]. One of the first in vivo evidences about the anticarcinogenic effects of SCC was conducted with rainbow trout. The final outcome of the study was that SCC salts dosed in the diet reduced hepatocarcinogenesis induced by aflatoxin B1 (AFB1) [102]. The authors also found that the SCC salts reduced the incidence of tumors in the liver, stomach and bladder and the effect was higher when administered simultaneously with benzo- $[\alpha]-$ pyrene (B-[a]-P) [103]. Further studies with animal models continued to show that SCC salts have anticarcinogenic properties [89, 104- 105]. Some other studies show that SCC salts protect animals from induced reagent tumorigenesis [88-89, 105] or as inhibitors of several mutagens [69]. The study of Egner et al. [106] focused in patients with a high risk of developing cancer, which were treated with SCC salts. The study was carried out in China, where hepatocellular carcinoma accounts for 300,000 deaths annually and it is the third leading cause of cancer mortality. This region has previously been identified as having an extremely high incidence of hepatocellular carcinoma with contributory factors including dietary exposure to aflatoxins and chronic hepatitis B infection. In the clinical trial, administration of SCC salts three times a day led to a 50\% reduction in the median level of urinary excretion of aflatoxin-N7-guanine, identified as a product derived from the ultimate carcinogenic metabolite of AFB1, aflatoxin-8, 9-epoxide [107], compared to the placebo group. Thus, the strategy of chemoprevention reducing the genotoxic and cytotoxic effects of aflatoxins in high-risk groups can considerably reduce/delay the appearance of hepatocellular carcinoma [108]. Surprisingly, SCC salts were described as tumor promoters for a dimethylhydrazine-induced colorectal cancer in rats [84]. The incidence and yield of colorectal tumors increased significantly in animals receiving supplementary SCC salts in the diet. 


\subsection{Photosensitizer-photodynamic therapy}

Chlorophylls, as other cyclic tetrapyrroles are photosensitizers. This means that in presence of light and molecular oxygen they are able to produce singlet oxygen (or other reactive forms of oxygen), ROS. These molecules are highly cytotoxic, able to cause apoptosis, necrosis and autophagy cellular, through direct oxidative damage or through a microvascular shutdown [109]. When a photosensitizer absorbs light of appropriate wavelengths, it is transformed from its ground electronic state to an excited to a short-lived single state. From this state, the photosensitizer is able to return to the ground state emitting the absorbed energy or can convert into an excited triplet by intersystem crossing. The excited triplet is long-lived enough to take part in two types of photodynamic chemical reactions: type I are electron or hydrogen-transfer producing reactive intermediates (as $\mathrm{O}_{2}^{-}$) or type II reactions, where ${ }^{3} \mathrm{O}_{2}$ is transformed in the highly reactive singlet oxygen $\left({ }^{1} \mathrm{O}_{2}\right)$, which is the main cytotoxic product [11].

The photodynamic therapy (PDT) is a treatment of cancer, alternative to radio or chemotherapy, much less invasive or aggressive, based on the capacity of the photosensitizer. This therapy presents several advantages as it can applied to places where surgery cannot be performed, it is a smoothly treatment (it can be applied to vulnerable patients), it has very low secondary reactions (e.g., it does not depress the immune system) and it does not exhibit any organ toxicity. The PDT is based on the administration, intravenous or intraperitoneal of a good photosensitizer. Chlorophylls are long-considered to be 'ideal drugs' for PDT as their photophysical properties meet the criteria for those excellent photosensitizers: the triplet-state yield is high, the tripletstate energy is higher than the energy of singlet state, and they are efficient in the energy transfer for the formation of ${ }^{1} \mathrm{O}_{2}$. In addition, they should absorb light of sufficient long wavelengths and preferably, should not absorb light of the region 400$600 \mathrm{~nm}$ [11]. Engagement of all these criteria is achieved through three structural features: the chromophore structure, the central metal ion and the peripheral substituents [109], which are feasible in the chlorophyll structure.

Several deep studies have reviewed the evolution of the modifications in the chemical structures of cyclic tetrapyrroles seeking the perfect photosensitizer since the end of the twenty century [11, 109-111]. Since the first approved and most important commercial photosensitizing drug was released, Photofrin ${ }^{\circledR}$, several trademarks have been registered in different countries, approved by health organizations or currently 
under human clinical trials. The first generation of photosensitizers was composed by hematoporphyrin (Hp, 24, Fig. 7) and its derivatives (HpD), being the most famous the already mentioned Photofrin ${ }^{\circledR}$ [112]. Several limitations in these products caused the development of the second generation of photosensitizers. The focuses of the new modifications/synthesis were to absorb light in longer wavelengths and with stronger absorptions, through different strategies: suitable substituents as in $m$-THPP (25, Fig. (7), temoporfin or Foscan $\left.{ }^{\circledR},[113]\right)$, expansion of the macrocyclic $\pi$-electron system producing phtalocyanines as Pc4 (26, Fig. 7) [114], reduction of one peripheral double bond as in chlorins (27, Fig. 7, $\mathrm{SnET}_{2}$, or Purlytin, or bacteriochlorins, replacing of one pyrrole ring with a phenyl ring as in texahyrins (28, Fig. 7, LuTex, Lutrin, [115] or benzoporphyrin derivative monoacid ring A (29, Fig. 7, BDP-MA or verteporfin, Visudyne®) [116].

Strictly speaking, although chlorophyll and its derivatives have suitable photophysical properties for PDT, besides its natural abundance, some of them are rarely used as photosensitizer due to their high tendency to form aggregates (chlorophyll $b$, pheophorbide $a$ and $b$ ) or poor solubility in physiological liquids (chlorophyll $a$, pheophytin $a$ ). Promising results showed the modifications over the pyropheophorbide $a$ molecule (12, Fig. 3), introducing different alkyl groups at C3 ${ }^{1}$ position, increasing not only the hydrophobicity but also the photosensitizing properties [11]. The hexyl ether of pyropheophorbide (HPPH) is known as Photochlor [44] (31, Fig. 8). Another chlorophyll derivative, chlorin $e_{6}$ (13, Fig. 4), exhibits great photosensitizing properties [11]. In fact, several derivatives of chlorin $e_{6}$ are under clinical trials or already commercialized. One of them is the mono L-aspartyl derivative of chlorin $e_{6}\left(32\right.$, Fig. 8, $\mathrm{MACe}_{6}, \mathrm{Npe}_{6}$, laserphyrin) which shows positive results in cutaneous and lung cancers, or Radachlorin ${ }^{\circledR}$ that it is a mixture of sodium chlorin $e_{6}$ and sodium chlorin $p_{6}(\mathbf{3 3 - 3 4}$, Fig. 8), that it is being tested in the treatment of several type of cancers [117]. The Roswell Park Cancer Institute is developing longwavelengths photosensitizers $(700-800 \mathrm{~nm})$ derived from methyl-pyropheophorbide (38, Fig. 8), or purpurin-18 methyl ester (39, Fig. 8). One strategy is replacing the five member isocyclic ring (E ring) with a fused six member imide ring system. And a further red-shift displacement is observed if additionally both B and D rings are reduced [110], reaching the absorption around $800 \mathrm{~nm}$. But besides the continuous research in the development of new modifications over the chlorophyll structures to obtain better photosensitizers, probably the future focus is to improve the specificity in the target 
tissue (for example by conjugation of the photosensitizer with monoclonal antibodies [118] and the delivery system [119].

The photosensitizing properties of chlorophylls are not only used in the PDT treatment of cancer, but also in cancer detection, which is fundamental in the early and exact diagnosis. In this sense, 'bifunctional agents' are developed with two objectives: tumor imaging and therapy [110]. The strategy is the conjugation of a tumor-avid porphyrin and other compound to obtain both effects at the same time. The detection is made using the fluorescence characteristics of porphyrins [120], magnetic resonance or nuclear imaging [121].

The overproduction of ROS during the PDT has attracted great attention as an effective approach to treat microbial infections [122]. Specifically, chlorin $e_{6}$ (13, Fig. 4)-metiated PDT with halogen light has inactivated various skin bacteria, including Propionibacterium acnes, proposing this methodology as an alternative therapy for acne vulgaris [123]. But the most promising functions of chlorophyll derivatives will be the control of several viral infections thanks to its photodynamic activity against insects. Wohllebe et al. [124] have shown that insect larvae die due to an induced necrosis and apoptosis generated in the intestine by the presence of chlorophyll derivatives and light exposure. Chlorophylls should be incubated in dark conditions for a few hours to accumulate in the larvae and subsequent exposure to light, for example applying chlorophyll derivatives to water at night, which will be accumulated in larvae and photodynamic reaction will start with the sunrise [7]. In this sense, chlorophyllin and pheophorbide are fatal to larvae of Culex and Chaoborus [125], chlorophyllin effectively kills Aedes and Anopheles species [126] and even chlorophyll derivatives are effective against the larvae of freshwater snail [127] and certain parasites of fish [128]. But in addition to laboratory tests, also field trials have been performed. Abdel Kader and El-Tayed [129] applied between 0.1-100 $\mu \mathrm{M}$ chlorophyll derivatives to $250000 \mathrm{~m}^{2}$ of infected swamps in Uganda, killing up to $100 \%$ of Anopheles gambiae larvae. Different insects are the vectors of viral infections as dengue, malaria or filarial, consequently chlorophyll derivatives have been proposed as effective weapons against these infections [7].

\subsection{Other biological functions}

Different SCC complexes (Fig. 5) have been investigated in relation to dermatologic disorders. Rosacea is a chronic illness of the skin that typically involves 
facial erythema, visible blood vessels and often papules and pustules. Although the etiology of this affliction is not well understood, the inflammatory cascade is the main objective of the present therapies [130]. In this sense, Vasily [131] has developed a formulation (Phytochromatic $\mathrm{MD}^{\mathrm{TM}}$ ) based on copper chlorophyllins (Fig. 5) with promising clinic results in the reduction of facial redness. A similar formulation containing a liposomal dispersion of sodium copper chlorophyllin complexes has been employed in a pilot study [132] with positive results. The topical formulation was shown to be clinically effective and well tolerated for the treatment of mild-moderate photodamage and solar lentigenes when used for 8 weeks. Different biomarkers of the healthy state of the skin (amount of fibrillin, procollagen I and mucins) increased statistically when skin biopsy samples of photoaged females are treated with liposomal dispersion of sodium copper chlorophyllin complex [8]. One of the proposed mechanisms responsible of the antiaging effect of copper chlorophyllins is through the inhibition of hyaluronidase [133]. Hyaluronic acid (HA) is one of the critical components of the extracellular matrix in tissues, necessary for maintaining normal hydration of human skin. In fact, HA is used as dermal filler for correction of facial lines and wrinkles. HA in tissues is degraded by hyaluronidases, which usually are inactive because they are bound to inhibitors. Although several compounds of the copper chlorophyllins complex shown in vitro inhibitory activity against hyaloronidase, copper (II) isochlorin $e_{4}(\mathbf{1 7}$, Fig. 5) was the most effective derivative [133].

But chlorophyll derivatives have also been studied in regard to their antimicrobial properties. Specifically, the combination of probiotic bacteria (Lactobacillus fermentum) and chlorophyllins have been analyzed in dogs [134]. The antimicrobial effect of chlorophyllins was manifested in decreased coliform and clostridial populations with no effect on lactic acid bacteria, proposing that chlorophyll additives might be helpful in the canine diet to prevent bacterial intestinal infections without disturbance of beneficial bacteria.

\section{Functions of chlorophylls at animal cell level}

One of the most surprising functions proposed for chlorophyll derivatives in mammals is the capacity to produce ATP [135]. Authors showed that upon incubation of isolated mice mitochondria and brain, heart and lens homogenates, homogenized duck fat, and alive Caenorhabditis elegans, with pyropheophytin $a$, the light exposure was able to increase ATP concentrations. It is proposed that the photoactivated 
pyropheophytin $a(\mathbf{1 2}$, Fig. 3) could catalyze the reduction of mitochondrial ubiquinone. The mechanism would imply that the electrons are transferred by a chlorophyll derivative from $\mathrm{CoQ}_{10}$, from an active chemical oxidant in the mitochondrial milieu (Fig. 9). Later, the same research group [136] showed that the photoreduced $\mathrm{CoQ}_{10}$ was able to reduce cytochrome $c$, linked with increased ATP concentrations and consistent with decreases in ADP and AMP pools. Authors have observed that C. elegans worms reduced their fat mass, up to $78 \%$ less, in presence of pheophytin $a$ and long wavelength light, modifying their fatty acid profile. In any case, although the excitation of the chlorophyll catabolite by light would expect to originate singlet oxygen species and oxidative damage, the animals showed less lipid and protein carbonyls, which mean less oxidative stress. Finally, they found an additional modification, also the immune system is altered, and the worms presented reduced plasma levels of $\alpha$-macroglobulin, an index of the systemic inflammation. Although further investigations are required, data are consistent with nuanced function of an organism by the combination chlorophylls and light.

Another important role for dietary chlorophylls is the possible function as antioxidant in the serum [137]. Ubiquinol-10 (known as CoQ) is considered a lipid antioxidant as it scavenges free radicals and it is also implicated in $\alpha$-tocopherol homeostasis. When ubiquinol performs its antioxidant function, it is oxidized to ubiquinone. The organism needs to restore the pool of ubiquinol in serum through a mechanism still not completely understood. In vitro, it has been shown that dietary chlorophylls available in serum are able to reduce plasma ubiquinone to ubiquinol in the presence of ambient light (Fig. 9). Consequently, it has been proposed that dietary chlorophyll could be implicated in the regulation of the plasma redox status.

Another completely different function has been also proposed for chlorophyll derivatives, their implication as visual pigments for vision in the red spectrum. The dim light vision in the red region of the spectra would impart a large biological advantage, mainly in conditions as haze, fog or underwater [138] due to the less light scattering in these wavelengths. In this sense, Douglas et al. [139] identified two chlorophyll derivatives in retinal cells, chlorobium pheophorbides 650 and $660 \mathrm{~nm}$, as responsible of the vision in the red spectrum of the deep-sea fish Malacosteus niger. Separately, the rods from a salamander accumulate an exogenous chlorophyll derivative that renders them to be sensitive to red light. In mammals, Washington et al. [140] have found a selective accumulation of chlorin $e_{6}(\mathbf{1 3}$, Fig. 4) in retinal cells after injecting it 
intravenously. They have demonstrated that such chlorophyll derivative is able to initiate the transformation of light into an electrical signal enhancing the vision in a mouse model.

Although the main research has been always focused in the functionality of the cyclic tetrapyrrole structure, phytol chain activity has recently gain interest. In fact, a recent study [141] has reviewed literature dealing with research related with phytyl chain. Phytol, $\mathrm{C}_{20} \mathrm{H}_{40}$ is an acyclic diterpene alcohol, present in intact chlorophylls and pheophytins $a$ and $b$. Phytyl chain is released from chlorophyll structure by enzymatic deesterification (chlorophyllase or pheophytinase) in the first reaction steps of the natural chlorophyll degradation pathway associated to plant senescence [17]. Indeed, phytol metabolites in animal tissues are exclusively derived from the phytyl side chain of chlorophylls. As a consequence of the consumption of large quantities of grass, ruminant animals contain high amounts of phytol derivatives. In the organism, phytol can be metabolized to different derivatives as phytenic acid, phytanic acid and pristanic acid (Fig. 10) through a pathway not completely understood [142]. The different reactions are developed between the endoplasmic reticulum and peroxisomes. While fatty acids are metabolized trough the $\beta$-oxidation pathway, where two carbon atoms are removed, phytanic acid is breakdown by the $\alpha$-oxidation route, where only one carbon atom is removed. This pathway is exclusive of peroxisomes organelles [142]. There are several metabolic disorders related with phytol metabolism. For example, Refsum disease [143] is characterized by a $\alpha$-hydroxylase gene defect that avoids phytanic acid conversion to pristanic acid. Consequently patients are characterized by an accumulation of phytanic acid. Sjcgren-Larsson syndrome (SLS) is an autosomal recessive disorder characterized by congenital ichthyosis, mental retardation, and spasticity [144], where patients accumulate long-chain aliphatic alcohols. Although the primary biochemical defect in SLS is unknown, it has been related with phytol metabolism [145]. At molecular level, phytol and its derivatives have been implicated in the activation of specific nuclear receptors. These nuclear receptors act as transcription factors that activate gene transcription are in a ligand-bound state. For example, it has been shown that phytol metabolites can activate the nuclear retinoid-X receptor (RXR) involved in the fatty acid metabolism [146]. Specifically, phytanic acid and phytenic acid quantified in the serum of bovine animals were able to stimulate RXR by direct interactions. In fact, authors determined that the phytol metabolites RXR binding affinities and activation potencies match with their micromolar circulation 
concentrations. Late investigations have shown that phytol metabolites specifically activate PPARs (peroxisome proliferator-activator receptors), which bind to RXT to form heterodimers and regulate the expression of their target genes. Although PPARs have three isoforms, PPAR $\alpha$ is the one responsible for the hepatic metabolism of foodderived fatty acids. Phytanic acid has been reported to activate PPAR $\gamma$ [147] and PPAR $\alpha$ [148] and consequently the differentiation of white [147] and brown [147] adipocytes. More recently, Goto et al. [149] have shown that phytol is able to activate PPAR $\alpha$ and upregulate the expression of PPAR $\alpha$-target genes at both mRNA and protein levels in PPAR $\alpha$-expressing HepG2 hepatocytes. Authors proposed that phytol itself could control lipid abnormalities in common diseases including obesity, diabetes, and hyperlipidemia.

\section{CONCLUSSIONS}

Originally, chlorophylls were exclusively associated with photosynthetic organisms, as a consequence of the essential role of these cyclic tetrapyrrole compounds in light harvesting or in charge separation in the reaction centers during photosynthesis. Certainly, the origin of chlorophyll metabolites present in the animal body are circumscribed to the ingestion of vegetables, algae, etc, that is, photosynthetic tissues. In this sense, chlorophyll metabolites were historically assumed to be unabsorbed at intestinal tissue, but excreted by the fecal route. Recent evidences [108] clearly showed that several chlorophyll derivatives accumulate in human serum when subjects are supplemented with a chlorophyllins rich diet, and that from certain levels chlorophylls could develop some function in the animal organism. According to this, most encouraging investigations are ongoing. The recent discovery of the ability of few chlorophyll metabolites in animal tissues under certain conditions to develop specific functions: to produce ATP, to reduce the plasma ubiquinone, as visual pigments, etc, probably opens a new research era. Presumably, in the future chlorophyll metabolites will not be only longer considered as merely secondary compounds from a green diet, but as truly phytochemicals.

One of the most necessary fields of study in these future investigations is the impact or influence of the chlorophyll structure on the bioactivity of the molecules. The capacity of a compound to work out a physiological role is based on its structural configuration. For example, the planar surfaces of chlorophylls allows the hydrophobic interaction with mutagens, or the capacity of chlorophylls to absorb light and to 
transform it into an electrical signal enhancing the vision, etc. At this respect there si a considerable work to do. Perhaps, in relation with the PDT, the existing knowledge of chlorophyll spectroscopic properties in relation to the molecule structure and the occurrence of clear objectives have allowed to succeed. Great advances have been made in relation to the development of better photosensitizers. On the contrary, although abundant research has been performed analyzing the antioxidant and antigenotoxic properties of chlorophylls, the results are diverse and in many investigations the molecular basis is still unknown. Perhaps, in this area it will worth to design future assays taking into account the nature of the chlorophyll compounds and their properties. As noted before, versatility is the main adjective of chlorophylls, which means to be prone for structural modifications that allow modification of solubility, affinity, etc, and consequently an extensive field where to investigate.

\section{LIST OF ABBREVIATIONS}

$\mathrm{AFB} 1=$ aflatoxin $\mathrm{B} 1$

$\mathrm{BDP}-\mathrm{MA}=$ Benzoporphyrin derivative monoacid ring A

$\mathrm{cDDP}=$ cistaplin

CoQ = Ubiquinol-10

DBC $=$ Polycyclic aromatic compounds

$\mathrm{DMPO}=5-5$ - dimethyl-1-pirroline-N-oxide)-OH

$\mathrm{DPPH}=$ 2,2-diphenyl-1-picrylhydrazyl

EFSA = European Food and Safety Authority

$\mathrm{ESR}=$ Electron spin resonance spectroscopy

FDA $=$ Food and Drug Administration

$\mathrm{GSH}=$ glutathione

$\mathrm{HA}=$ Hyaluronic acid

$\mathrm{Hp}=$ Hematoporphyrin

$\mathrm{HpD}=$ Hematoporphyrin derivatives

$\mathrm{HPPH}=$ hexyl ether of pyropheophorbide

IUPAC-IUB = International Union of Pure and Applied Chemistry -International Union of Biochemistry.

$\mathrm{MACe}_{6}=$ mono L-aspartyl derivative of chlorin $\mathrm{e}_{6}$

$\mathrm{MB}=$ Methylene blue

PDT $=$ Photodynamic therapy 
PPAR $=$ Peroxisome proliferator-activator receptors

ROS $=$ reactive oxygen species

$\mathrm{RXR}=$ Nuclear retinoid $\mathrm{X}$ receptor

SCC $=$ Sodium copper chlorophyllins

SOD = superoxide dismutase

TBARS $=$ Thiobarbituric acid reactive substances

$m$-THPP = meso-tetra-hydroxyphenil-chlorin

\section{CONFLICT OF INTEREST}

The authors confirm that this article content has no conflict of interest.

\section{ACKNOWLEDGEMENTS}

This work was supported by the Comisión Interministerial de Ciencia y Tecnología (CICYT-EU, Spanish and European Government, AGL 2015-63890-R).

\section{REFERENCES}

[1] Chen, K.; Rios, J.J.; Pérez-Gálvez, A.; Roca, M. Development of an accurate and high-throughput methodology for structural comprehension of chlorophylls derivatives. (I) Phytylated derivatives. J. Chromatogr. A, 2015, 1406, 99-108.

[2] Chen, K.; Rios, J.J.; Roca, M.; Pérez-Gálvez, A. Development of an accurate and high-throughput methodology for structural comprehension of chlorophylls derivatives. (II) Dephytylated derivatives. J. Chromatogr. A, 2015, 1412, 90-99.

[3] Ulbricht, C.; Bramwell, R.; Catapang, M.; Giese, N.; Thuy-Duong Le, R.I.; Montalbano, J., Tanguay-Colucci., S.; Trelour, N., Wendy W.; Windsor, R.; Wortley, J.; Yoon, H.; Zeolla, M.. An Evidence-Based Systematic Review of Stevia by the Natural Standard Research Collaboration. J. Diet. Suppl., 2014, 11, $80-120$.

[4] Ferruzzi, M.G.; Böhm, V.; Courtney, P.D.; Schwartz, S.J. Antioxidant and antimutagenic activity of dietary chlorophyll derivatives determined by radical scavenging and bacterial reverse mutagenesis assays. J. Food Sci., 2002, 67, 2589-2595.

[5] Jonker, J.W.; Buitelaar, M.; Wagenaar, E.; van der Valk, M.A.; Scheffer, G.L.; Scheper, R.J.; Plösch, T.; Kuipers, F.; Elferink, R.P.J.O.; Rosing, H.; Beijnen, J.H.; Schinkel, A.H. The breast cancer resistance protein protects against a major 
chlorophyll-derived dietary phototoxin and protoporphyria. Proc. Natl. Acad. Sci. U.S.A. 2002, 99, 15649-15654.

[6] Ferruzzi, M.G; Blakeslee, J. Digestion, absorption, and cancer preventative activity of dietary chlorophyll derivatives. Nutr. Res. 2007, 27, 1- 12.

[7] Azizullah, A.; Rehman, Z.R.; Ali, I.; Murad W.; Muhammad, N.; Ullah, W.; Häder, D.P. Chlorophyll derivatives can be an efficient weapon in the fight against dengue. Parasitol Res., 2014, 113, 4321-4326.

[8] McCook, J.P.; Stephens, T.H.; Jiang, L.I.; Law, R.M.; V. Ability of sodium copper chlorophyllin complex to repair photoaged skin by stimulation of biomarkers in human extracellular matrix. Clin. Cosmet. Investig. Dermatol., 2016, 9, 167-174.

[9] Hynninen, P.H. IV. Preparation and purification of some derivatives of chlorophylls a and b. Acta Chem. Scan., 1973, 27, 1171-1780.

[10] Hartwich, G.; Fiedor, L.; Simonin, I.; Cmiel, E.; Schäfer, W.; Noy, D.; Scherz, A.; Scheer, H. Metal-substituted bacteriochlorophylls. 1. Preparation and influence of metal and coordination on spectra. J. Am. Chem. Soc., 1998, 120, 3675-3683.

[11] Nyman, E.S.; Hynninen, P.H. Research advances in the use of tetrapyrrolic photosensitizers for photodynamic therapy. J. Photochem. Photobiol. B, 2004, 73, $1-28$.

[12] Szczygiel, M.; Urbanska, K.; Jurecka, P.; Stawoska, I.; Stochel, G.; Fiedor, L. Central metal determines pharmacokinetics of chlorophyll-derived xenobiotics. $J$. Med. Chem., 2008, 51, 4412-4418.

[13] Scheer, H. An overview of chlorophylls and bacteriochlorophylls: biochemistry, biophysics, functions and applications In: Chlorophylls and Bacteriochlorophylls: Biochemistry, Biophysics, Functions and Applications; Grimm, Porra, Rüdiger, Scheer, Eds.; Springer: The Netherlands, 2006; pp. 1-26.

[14] Schwartz, S.J.; Lorenzo, T.V. Chlorophylls in foods. Crit. Rev. Food Sci. Nutr., 1990, 29, 1-17.

[15] Costa, M.L.; Civello, P.M.; Chaves, A.R.; Martínez, G.A. Characterization of Mgdechelatase activity obtained from Fragaria $\times$ ananassa fruit. Plant Physiol. Biochem., 2002, 40, 111-118

[16] Suzuki, T.; Kunieda, T.; Murai, F.; Morioka, S.; Shioi, Y. Mg-dechelation activity in radish cotyledons with artificial and native substrates, Mg-chlorophyllin $a$ and chlorophyllide $a$. Plant Physiol. Biochem., 2005, 43, 459-464. 
[17] Guyer, L.; Hofstetter, S.S.; Christ, B.; Lira, B.S.; Rossi, M.; Hörtensteiner, S. Different mechanisms are responsible for chlorophyll dephytylation during fruit ripening and leaf senescence in tomato. Plant Physiol., 2014, 166, 44-56.

[18] Vergara-Domínguez, H.; Gandul-Rojas, B.; Roca, M. Formation of oxidised chlorophyll catabolites in olives. J. Food Comp. Anal., 2011, 24, 851-857.

[19] Hynninen, P.H.; Leppakasesa, T.S.; Mesilaakso, M. Demethoxycarbonylation and oxidation of $13^{2}(\mathrm{~S} / \mathrm{R})$-hydroxychlorophyll $a$ to $13^{2}$-demethoxycarbonyl-13 ${ }^{2}$-oxochlorophyll $a$ and Mg-purpurin-18 phytyl ester. Tetrahedron Letters, 2006, 47, 1663-1668.

[20] Scotter, M.J. Methods for the determination of European Union-permitted added natural colours in foods: a review. Food Addit. Contam., 2011, 28, 527-596.

[21] United States Food and Drug Administration. Summary of Color Additives for Use in the United States in Foods, Drugs, Cosmetics, and Medical Devices. http://www.fda.gov/ForIndustry/ColorAdditives/ColorAdditiveInventories/ucm1 1 5641.htm. (Accessed December 28, 2016).

[22] European Union Legislation on food additives. Official Journal of the Commission of the European Communities. Regulation (EC) No 1333/2008. http://eurlex.europa.eu/legal-content/EN/TXT/?uri=CELEX:32008R1333 (Accessed December 28, 2016).

[23] EFSA Panel on Food Additives and Nutrient Sources added to Food . Scientific Opinion on re-evaluation of chlorophyllins (E 140(ii)) as food additives. EFSA J., 2015, 13, 4085.

[24] Chernomorsky, S.; Rancourt, R.; Sahai, D.; Poretz, R. Evaluation of commercial chlorophyllin copper complex preparations by liquid chromatography with photodiode array detection. J. of AOAC International, 1997, 80, 433-435.

[25] Inoue, H.; Yamashita, K.; Furuya, K.; Nonomura, Y.; Yoshioka, N.; Li, S. Determination of copper (II) chlorophyllin by reversed-phase high-performance liquid chromatography. J. Chromatograph., 1994, 679, 99-104.

[26] Mortensen, A.; Geppel, A. HPLC-MS analysis of the green food colorant sodium copper chlorophyllin. Innov. Food Sci. Emerg. Tech., 2007, 8, 419-425.

[27] Scotter, M.J.; Castle, L.; Roberts, D. Method development and HPLC analysis of retail foods and beverages for copper chlorophyll (E141[i]) and chlorophyllin (E141[ii]) food colouring materials. Food Addit. Contam., 2005, 22, 1163-1175. 
[28] EFSA Panel on Food Additives and Nutrient Sources added to Food . Scientific Opinion on re-evaluation of chlorophyllins (E 141(ii)) as food additives. EFSA J., 2015, 13, 4155 .

[29] Katz, J.J. Chlorophyll interactions and light conversion in photosynthesis. Naturwissenschaften 1973, 60, 32-39.

[30] Agostiano, A.; Catucci, L.; Colafemmina, G.; Scheer, H. Role of functional groups and surfactant charge in regulating chlorophyll aggregation in micellar solutions. J. Phys. Chem. B 2002, 106, 1446-1454.

[31] Oba, T.; Furukawa, H.; Wang, Z.Y., Nozawa, T.; Mimuro, M.; Tamiaki, H.; Watanabe, T. Supramolecular structures of the chlorophyll a' aggregate and the origin of the diastereoselective separation of chlorophyll a and a'. J. Phys. Chem., 1998, 102, 7882-7889.

[32] Agostiano, A.; Cosma, P.; Trotta, M.; Monsu-Scolaro, L.; Micali, N. Chlorophyll $a$ Behavior in Aqueous Solvents: Formation of Nanoscale Self-Assembled Complexes. J. Phys. Chem. B 2002, 106, 12820-12829.

[33] Robey, R.W.; Steadman, K.; Polgar, O.; Morisaki, K.; Blayney, M.; Mistry, P.; Bates, S.E. Pheophorbide $a$ is a specific probe for ABCG2 function and inhibition. Cancer Res., 2004, 64, 1242-1246.

[34] Weiss, C. Optical spectra of chlorophylls In: The porphyrins; Dolphin, Ed.; Academic Press: New York, 1978; pp. 211-224.

[35] Steiner, E.; Soncini, A.; Fowler, P.W. Ring currents in the porphyrins: $\pi$ shielding, delocalization pathways and the central cation. Org. Biomol. Chem., 2005, 3, 4053-4059.

[36] Fiedor, L.; Kania, A.; Mysliwa-Kurdziel, B.; Orzel, L.; Stochel, G. Understanding chlorophylls: central magnesium ion and phytyl as structural determinants. $B B A$ Bioenergetics, 2008, 1777, 1491-1500.

[37] Drzewiecka-Matuszek, A.; Skalna, A.; Karocki, A.; Stochel, G.; Fiedor, L. Effects of heavy central metal on the ground and excited states of chlorophyll. J. Biol. Inorg. Chem., 2005, 10, 453-462.

[38] Küpper, H.; Küpper, F.C.; Spiller, M. [Heavy metal]-chlorophylls formed in vivo during metal stress and degradation products formed during digestion, extraction and storage of plant material In: Chlorophylls and Bacteriochlorophylls; Grimm, B.; Porra, R.J.; Rüdiger, W., Scheer, H., Eds.; Springer: Dordrecht, 2006; Vol. 25, pp. 67-77. 
[39] Beukeveld, G.; Woithers, B.; van Saene, J.; de Haan, T.; de Ruyter-Buitenhuis, L.; van Saene, R. Patterns of porphyrin excretion in feces as determined by liquid chromatography; reference values and the effect of flora suppression. Clin. Chem., 1987, 33, 2164-2170.

[40] Rosenbach-Belkin, V.; Chen, L.; Fiedor, L.; Tregub, I.; Pavlotsky, F.; Brumfeld, V.; Salomon, Y.; Scherz, A. Serine conjugates of chlorophyll and bacteriochlorophyll: Photocytotoxicity in vitro and tissue distribution in mice bearing melanoma tumors. Photochem. Photobiol., 1996, 64, 174-181.

[41] Mazor, O.; Brandis, A.; Plaks, V.; Neumark, E.; Rosenbach-Belkin, V.; Salomon, Y.; Scherz, A. WST11, a novel water-soluble bacteriochlorophyll derivative: cellular uptake, pharmacokinetics, biodistribution and vascular-targeted photodynamic activity using melanoma tumors as a model. Photochem. Photobiol., 2005, 81, 342-351.

[42] Woodward, R.B.; Ayer, W.A.; Beaton, J.M.; Bickelhaupt, F.; Bonnet, R.; Buchschacher, P.; Closs, G.L.; Dutler, H.; Hannah, J.; Hauck, F.P.; Ito, S.; Langemann, A.; Le Goff, E.; Leimgurber, W.; Lwowski, W.; Sauer, J.; Valenta, Z.; Volz, H. The total synthesis of chlorophyll a. Tetrahedron, 1990, 46, 75997659 .

[43] Fiedor, L.; Stąsiek, M.; Myśliwa-Kurdziel, B.; Strzałka, K. Phytol as one of the determinants of chlorophyll interactions in solution. Photosynth. Res., 2003, 78, 47-57.

[44] Pandey, R.K.; Sumlin, A.B.; Constantine, S.; Aoudia, M.; Potter, W.R.; Bellnier, D.A.; Henderson, B.W.; Rodgers, M.A.; Smith, K.M.; Dougherty, T.J. Alkyl ether analogs of chlorophyll-a derivatives: Part 1. Synthesis, photophysical properties and photodynamic efficacy. Photochem. Photobiol., 1996, 64, 194-204.

[45] Henderson, B.W.; Bellnier, D.A.; Greco, W.R.; Sharma, A.; Pandey, R.K.; Vaughan, L.; Weishaupt, K.R.; Dougherty, T.J. A quantitative structure-activity relationship for a congeneric series of pyropheophorbide derivatives as photosensitizers for photodynamic therapy. Cancer Res., 1997, 47, 4000-4007.

[46] Gryshuk, A.; Chen, Y.; Goswami, L.N.; Pandey, S.; Missert, J.R.; Ohulchanskyy, T.; Potter, W.; Prasad, P.N.; Oseroff, A.; Pandey, R.K. Structure-activity relationship among purpurinimides and bacteriopurpurinimides trifluoromethyl substituent enhanced the photosensitizing efficacy. J. Med. Chem., 2007, 50, 1754-1767. 
[47] Zheng, G.; Aoudia, M.; Lee, D.; Rodgers, M.A.; Smith, K.M.; Dougherty, T.J.; Pandey, R.K. Chlorin-based symmetrical and unsymmetrical dimers with amide linkages: effects of the substituents on photodynamic and photophysical properties. J. Chem. Soc. Perkin Trans., 2000, 1, 3113-3121.

[48] Sies, H. Biochemistry of oxidative stress. Angew. Chem. Int. Ed. Engl., 1986, 25, $1058-1071$.

[49] Halliwell, B. Antioxidants in human health and disease. Annu. Rev. Nutr., 1996, $16,33-50$.

[50] Solymosi, K.; Mysliwa-Kurdziel, B. Chlorophylls and Their Derivatives Used in Food Industry and Medicine. Mini. Rev. Med. Chem., 2017, 17, 000-000.

[51] Marquez, U.; Barros, R.; Sinnecker, P. Antioxidant Activity of Chlorophylls and their Derivatives. Food Res. Int., 2005, 38, 885-891.

[52] Kamat, J.; Boloor, K.: Devasagayam, T.P. Chlorophyllin as an Effective Antioxidant against Membrane Damage in Vitro and ex Vivo. Biochim Biophys Acta, 2000, 147, 113-127.

[53] Zimmering, S.; Olvera, O.; Hernandez, M. E.; Cruces, M. P.; Arceo, C.; Pimentel, E. Evidence for a radioprotective effect of chlorophyllin in Drosophila. Mut. Res., 1990, 245, 47-49.

[54] Pimentel, E.; Cruces M.P; Zimmering, S. On the persistence of the radioprotective effect of chlorophyllin (CHLN) in somatic cells of Drosophila. Mutat. Res. Gen. Tox. En., 1999, 446, 189-192.

[55] Kumar, S.S.; Devasagayam, T.P.A.; Bhushan, B.; Verma, N.C. Scavenging of reactive oxygen species by chlorophyllin: an ESR study. Free Radical Res., 2001, 35, $563-574$.

[56] Sato, M.; Fujimoto, I.; Sakai, T.; Arimoto, T.; Kimura, T. Effect of sodium copper chlorophyllin on lipid peroxidation. IX. On the antioxidative components in commercial preparations of sodium copper chlorophyllin. Chem Pharm. 1986, 34 , 2428-2438.

[57] Egner, P.A.; Stansbury, K.H.; Snyder, E.P.; Rogers, M.E.; Hintz, P.A.; Kensler, T.W. Identification and Characterization of Chlorin e4 Ethyl Ester in Sera of Individuals Participating in the Chlorophyllin Chemoprevention Trial. Chem. Res. Toxicol., 2000, 13, 900-906.

[58] Gomes, B.; Barros, S.; Andrade-Wartha, E., Silva,A.; Silva, V.; Lanfer-Marqueza U. Bioavailability of dietary sodium copper chlorophyllin and its effect on 
antioxidant defence parameters of Wistar rats. J. Sci. Food Agric., 2009, 89, 2003-2010.

[59] Sato, M; Imai, K; Kimura, R, Murata, T. Effect of Sodium Copper Chlorophyllin on lipid peroxidation. VI. Effect of its administration on mitochondrial and microsomal lipid peroxidation in rats liver. Chem. Pharm. Bull., 1984, 32, 716722.

[60] Endo, Y.; Usuki, R.; Kaneda, T. Antioxidant Effects of Chlorophyll and Pheophytin on the Autoxidation of Oil Inducers of Mammalian Phase 2 Cytoprotective Genes. Carcinogenesis, 2005, 26(7), 1247-1255.

[61] Ong, T.M.; Whong, J.; Stewart, J.; Brockman, H.E. Comparative antimutagenicity of 5 compounds against 5 mutagenic complex mixture in Salmonella typhimurim stain TA 98. Mutat. Res., 1989, 222, 19-25.

[62] Islam, M.N.; Ishita, I.J.; Jin, S.E.; Choi, R.J.; Lee, C.M.; Kim, Y.S.; Jung, H.A.; Choi, J.S. Anti-inflammatory activity of edible brown alga Saccharina japonica and its constituents pheophorbide a and pheophytin a in LPS-stimulated RAW 264.7 macrophage cells. Food Chem. Toxicol., 2013, 55, 541-548.

[63] Subramoniam, A.; Asha, V.V.; Nair, S.A.; Sasidharan, S.P.; Sureshkumar, P.K.; Rajendran, K.N.; Karunagaran, D.; Ramalingam, K. Chlorophyll revisited: antiinflammatory activities of chlorophyll a and inhibition of expression of TNF-a gene by the same. Inflammation, 2012, 35, 959-966.

[64] Hsu, C.Y.; Chao, P.Y.; Hu, S.P.; Yang, C.M. The Antioxidant and Free Radical Scavenging Activities of Chlorophylls and Pheophytins. Food Nutr. Sci., 2013, 4, $1-8$.

[65] Hsu, C.; Yang, C.; Chen., C.; Chao, P.; Hu, S. Effects of Chlorophyll-Related Compounds on Hydrogen Peroxide Induced DNA Damage within Human Lymphocytes. J. Agric. Food Chem., 2005, 53, 2746-2750.

[66] Pangestuti, R.; Kim, S.K. Biological activities and health benefit effects of natural pigments derived from marine algae. J. Funct. Foods, 2011, 3, 255-266.

[67] Hong, C.O.; Nam, M.H.; Oh, J.S.; Lee, J.W.; Kim, C.T.; Park, K.W.; Lee, D.H.; Lee. K.W. Pheophorbide a from Capsosiphon fulvescens Inhibits Advanced Glycation End Products Mediated Endothelial Dysfunction. Planta Med., 2016, $82,46-57$.

[68] Chan, J.Y.; Tang, P.M.; Hon, P.M.; Au, S.W.; Tsui, S.K.; Waye, M.M.; Kong, S.K.; Mak, T.C.; Fung, K.P. Pheophorbide $a$, a major antitumor component 
purified from Scutellaria barbata, induces apoptosis in human hepatocellular carcinoma cells. Planta Med., 2006, 72(1), 28-33.

[69] Sarkar, D.; Sharma, A.; Talukder, G. Chlorophyll and chlorophyllin as modifiers of genotoxic effects. Mutat. Res., 1994, 318, 239-247.

[70] Negishi, T.; Rai, H.; Hayatsu, H. Antigenotoxicity of natural chlorophylls. Mutat. Res., 1997, 376, 97-100.

[71] Kimm, S.; Park, S.; Kang, S. Antimutagenic activity of chlorophyll to direct- and indirect-acting mutagens and its contents in the vegetables, Korean J. Biochem., 1982, $14,1-8$.

[72] Lai, C. Chlorophyll: The active factor in wheat sprout extract inhibiting the metabolic activation of carcinogens in vitro. Nutr. Cancer, 1979. 1, 19-21.

[73] Lai, C.; Butler M.A. Matney, T.S. Antimutagenic activities of common vegetables and their chlorophyll content. Mutation Res., 1980, 77, 245-250.

[74] Okai, Y.; Higgashi-Okai, K.; Yano, Y.; Otani S. Identification of antimutagenic substances in an extract of edible red alga, Porphyra tenera (Asadusa-nori). Cancer Lett., 1996, 100, 235-240.

[75] Yoshikawa, K.; Inagaki, K.; Terashita, T.; Shishiyama, J.; Kuo, S.; Shankel, D.M. Antimutagenic activity of extracts from Japanese eggplant. Mutation Res., 1996, 371, 65-71.

[76] Arimoto, S.; Negishi, T.; Hayatsu, H. Inhibitory effect of heroin on the mutagenic activities of carcinogens. Cancer Lett., 1980, 11, 29-33.

[77] Katoh, Y.; Nemoto, N.; Tanaka, M.; Takayama, S. Inhibition of benzo(a)pyreneinduced mutagenesis in Chinese hamster V79 cells by hemin and related compounds, Mutation Res., 1983, 121, 153-157.

[78] Mietzner, R. Testing meat extracts for mutagenic action. Fleischwirtschaft, 1981, 61, 1586-1588.

[79] Dashwood, R.; Guo, D. Antimutagenic potency of chlorophyllin in the Salmonella assay and its correlation with binding constants of mutagen-inhibitor complexes. Environ. Mutagen., 1993, 22, 164-171.

[80] Arimoto, S.; Ohara, Y.; Namba, T. Negishi, T.; Hayatsu, H. Inhibition of the mutagenicity of amino acid pyrolysis products by heroin and other biological pyrrole pigments. Biochem. Biophys. Res. Commun., 1980, 92, 662-668. 
[81] Hayatsu, H.; Negishi, T.; Arimoto, S.; Hayatsu, T. Porphyrins as potential inhibitors against exposure to carcinogens and mutagens. Mutat. Res., 1993, 290, 79-85.

[82] Ong, T.; Whong, W.Z.; Stewart, J.; Brockman, H.E. Chlorophyllin: a potent antimutagen against environmental and dietary complex mixtures. Mutat. Res., 1986, $173,111-115$.

[83] Waters, M.D.; Stack, H.F.; Jackson, M.A.; Brockman, H.E.; De Flora, S. Activity profiles of antimutagens: in vitro and in vivo data. Mutat. Res., 1996, 350, 109129.

[84] Nelson, R.L. Chlorophyllin, an antimutagen, acts as a tumor promoter in the ratdimethylhydrazine colon carcinogenesis model. Anticancer Res., 1992, 12, 737740.

[85] Ames, B.C.; McCann, J.; Yamasaki, E. Methods for detecting carcinogens and mutagens with the salmonella/mammalian-microsome mutagenicity test. Mutat. Res., 1975, 31, 347-364.

[86] Warner J.R.; Nath J.; Ong T.M. Antimutagenicity studies of chlorophyllin using the Salmonella arabinose-resistant assay system. Mutat. Res. Lett., 1991, 262, 2530.

[87] Chung, W.Y.; Lee, J.M.; Lee, W.Y.; Surh Y.J.; Park, K.K. Protective effects of hemin and tetrakis (4-benzoic acid) porphyrin on bacterial mutagenesis and mouse skin carcinogenesis induced by 7,12-dimethylbenz[a]anthracene. Mutat. Res. Gen. Tox. En., 2000, 472(1), 139-145.

[88] Breinhold, V.; Hendrick, J.; Pereins, C.; Arbogast, D.; Bailey, G. Dietary chlorophyllin is a potent inhibitor of aflatoxin B1 hepatocarcinogenesis in rainbow trout. Cancer Res., 1995, 55, 57-62.

[89] Guo, D.; Horio, D.T.; Grove, J.S.; Dashwood, R.H. Inhibition by chlorophyllin of 2-amino-3-methylimidazo-[4,5-f]quinoline-induced tumorigenesis in the male F344 rat. Cancer Lett., 1995, 95, 161-165.

[90] Tachino, N.; Guo, D.; Dashwood, W.M.; Yamane, S.; Larsen, R.; Dashwood, R. Mechanisms of the in vitro antimutagenic action of chlorophyllin against benzo[a]pyrene: studies of enzyme inhibition, molecular complex formation and degradation of the ultimate carcinogen, Mutat. Res., 1994, 308, 191-203. 
[91] Arimoto, S.; Fukuoka, S.; Itome, C.; Nakano, H.; Rai, H.; Hayatsu, H. Binding of polycyclic planar mutagens to chlorophyllin resulting in inhibition of the mutagenic activity. Mutat. Res., 1993, 287, 293-305.

[92] Pimentel, E.; Cruces, M.P.; Zimmering, S. A Further Study of the Role of Copper in Regard to the Antimutagenic Action of Sodium Copper Chlorophyllin (SCC) in Somatic Cells of Drosophila melanogaster. Biomark Insights, 2013, 8, $29-33$.

[93] Norman, M.; Bartczak, P.; Zdarta, J.; Tomala, W.; Żurańska, B.; Dobrowolska, A.; Piasecki, A.; Czaczyk, K.; Ehrlich, H.; Jesionowski, T. Sodium Copper Chlorophyllin Immobilization onto Hippospongia communis Marine Demosponge Skeleton and Its Antibacterial Activity. Int. J. Mol. Sci., 2016, 17, 1564-1581.

[94] Arimoto, S.; Hayatsu, H. Role of hemin in the inhibition of mutagenic activity of 3-amino-1-methyl-5H-pyrido [4,3- b]indole (Trp-P-2) and other aminoazaarenes. Mutat. Res., 1989, 213, 217-226.

[95] Arimoto, S.; Kanyama, K.; Rai, H.; Hayatsu, H. Inhibitory effect of hemin, chlorophyllin and related pyrrole pigments on the mutagenicity of benzo[a]pyrene and its metabolites. Mutat. Res., 1995, 345, 127-135.

[96] Bronzetti, G.; Galli A.; Della Croce, C. Antimutagenic effects of chlorophyllin. Basic Life Science, 1990, 52, 463-468.

[97] Bailey, G.S.; Reddy, A.P.; Pereira, C.B.; Harttig, U.; Baird, W.; Spitsbergen, J.M.; Hendricks, J.D.; Orner, G.A.; Williams, D.E.; Swenberg, J.A.; Nonlinear cancer response at ultralow dose: a 40800-animal $\mathrm{ED}(001)$ tumor and biomarker study. Chem. Res. Toxicol., 2009, 22, 1264-1276.

[98] McQuistan, T. J.; Simonich, M.T.; Pratt, M.M.; Pereira, C.B.; Hendricks, J.D.; Dashwood, R.H.; Williams, D.E.; Bailey, G.S. Cancer chemoprevention by dietary chlorophylls: A 12,000-animal dose-dose matrix biomarker and tumor study. Food Chem. Toxicol., 2012, 50, 341-352

[99] Vogel J.; Jonker-Termont DS.; van Lieshout EM, Katan MB.; van der Meer R. Green vegetables, red meat and colon cancer: chlorophyll prevents the cytotoxic and hyperproliferative effects of haem in rat colon. Carcinogenesis, 2005, 26, 387-393.

[100] Serpeloni, J.M.; Batista, B.L.; Angeli, J.P.F.; Barcelos, G.R.M.; Bianchi, M.D.P.; Barbosa, F.; Antunes, L.M.G. Antigenotoxic properties of chlorophyll $b$ against cisplatin-induced DNA damage and its relationship with distribution of platinum and magnesium in vivo. J. Toxicol. Environ. Health A, 2013, 76, 345-353. 
[101] Nagini, S.; Palitti, F.; Natarajan, A.T. Chemopreventive potential of chlorophyllin: a review of the mechanisms of action and molecular targets. Nutr. Cancer, 2015, 67, 1-9.

[102] Breinhold, V.; Schimerlik, M.; Dashwood, R.; Bailey, G. Mechanisms of chlorophyllin anticarcinogenesis against aflatoxin B1: complex formation with the carcinogen. Chem. Res. Toxicol,. 1995, 8(4), 506-514.

[103] Reddy, A.P.; Harttig, U.; Barth, M.C.; Baird, W.M.; Schimerlik, M.; Hendricks, J.D.; Bailey, G.S. Inhibition of dibenzo [a, 1] pyrene-induced multi-organ carcinogenesis by dietary chlorophyllin in rainbow trout. Carcinogenesis, 1999, 20(10), 1919-1926.

[104] Hasegawa, R.; Hirose, M.; Kato, T.; Hagiwara, A.; Boonyaphiphat, P.; Nagao, M. Ito, N.; Shirai, T. Inhibitory effect of chlorophyllin on PhIP-induced mammary carcinogenesis in female F344 rats. Carcinogenesis, 1995, 16, 2243-2246.

[105] Park, K.K.; Surh, Y.J. Chemopreventive activity of chlorophyllin against mouse skin carcinogenesis by benzo(a)pyrene and benzo(a)pyrene-7,8-dihydrodiol-9,10epoxide, Cancer Lett., 1996, 102, 143-149.

[106] Egner, P.A.; Wang, J.B.; Zhu, Y.R.; Zhang, B.C.; Wu, Y.; Zhang, Q.N.; Qian, G.S.; Kuang, S.Y.; Gange, S.J.; Jacobson, L.P.; Helzlsouer, K.J.; Bailey, G.S.; Groopman, J.D.; Kensler, T.W. Chlorophyllin intervention reduces aflatoxinDNA adducts in individuals at high risk for liver cancer. Proc. Natl. Acad. Sci. USA, 2001, 98, 14601-14606.

[107] Essigmann, J.; Croy, R.; Nadzan, A.; Busby, W.; Reinhold, V.; Buchi, G.; Wogan, G. Structural identification of the major DNA adduct formed by aflatoxin B1 in vitro. Proc. Natl. Acad. Sci., 1977, 74, 1870-1874.

[108] Egner, P.A.; Muñoz, A.; Kensler, T.W. Chemoprevention with chlorophyllin in individuals exposed to dietary aflatoxin. Mutat. Res., 2003, 523, 209-216.

[109] Staroń, J.; Boroń, B.; Karcz, D; Szczygieł, M.; Fiedor, L. Recent Progress in Chemical Modifications of Chlorophylls and Bacteriochlorophylls for the Applications in Photodynamic Therapy. Curr. Med. Chem., 2015, 22, 3054-3074.

[110] Ethirajan, M.; Chen, Y.; Joshi, P.; Pandey, R.K. The role of porphyrin chemistry in tumor imaging and photodynamic therapy. Chem. Soc. Rev., 2011, 40, 340-362.

[111] Pandey, R.K.; Kessel, D.; Dougherty, T.J. Handbook of Photodynamic Therapy: Updates on Recent Applications of Porphyrin-Based Compounds. World Scientific: Singapore, 2016. 
[112] Dougherty, T.J.; Marcus, S.L. Photodynamic therapy. Eur. J. Cancer A, 1992, 28, 1734-1742.

[113] Nathan, T.R.; Whitelaw, D.E.; Chang, S.C.; Lees, W.R.; Ripley, P.M.; Payne, H.; Jones, L.; Parkinson, M.C.; Emberton, M.; Gillams, A.R.; Mundy, A.R.; Bown, S.G. Photodynamic therapy for prostate cancer recurrence after radiotherapy: a phase I study. J. Urol., 2002, 168, 1427-1432.

[114] O’Connor, A.E.; Gallagher, W.M.; Byrne, A.T. Porphyrin and nonporphyrin photosensitizers in oncology: preclinical and clinical advances in photodynamic therapy. Photochem. Photobiol., 2009, 85, 1053-1074.

[115] Dimofte, A.; Zhou, T.C.; Hahn S.M.; Lustig, R.A. In vivo light dosimetry for motexafin lutetium-mediated PDT of recurrent breast cancer. Lasers Surg. Med., 2002, 31, 305-312.

[116] Huggett, M.T.; Jermyn, M.; Gillams, A.; Illing, R.; Mosse, S.; Novelli, M.; Kent, E.; Bown, S.G.; Hasan, T.; Pogue, B.W.; Pereira, S.P. Phase I/II study of verteporfin photodynamic therapy in locally advanced pancreatic cancer. $B r . J$. Cancer., 2014, 110(7), 1698-1704.

[117] Mirzaei, H.; Djavid, G.E.; Hadizadeh, M.; Jahanshiri-Moghadam, M.; Hajian, P.J. The efficacy of Radachlorin-mediated photodynamic therapy in human hepatocellular carcinoma cells. Photochem. Photobiol. B., 2015, 142, 86-91.

[118] Ethirajan, M.; Patel, N. J.; Pandey, R.K. Porphyrin-based multifunctional agents for tumor-imaging and therapy (PDT) In: Handbook of Porphyrin Science with Applications to Chemistry, Physics, Materials Science, Engineering, Biology and Medicine; Kadish, Smith, Guilard, Eds.; World Scientific: Singapore, 2010; Vol. 4, pp. 249-323.

[119] Jenkins, S.V.; Srivatsan, A.; Reynolds, K.Y.; Gao, F.; Zhang, Y.; Heyes, C.D.; Pandey, R.K.; Chen, J. Understanding the interactions between porphyrincontaining photosensitizers and polymer-coated nanoparticles in model biological environments. J. Colloid Interface Sci., 2016, 461, 225-231.

[120] Patel, N.; Pera, P.; Joshi, P.; Dukh, M.; Tabaczynski, W.A.; Siters, K.E.; Kryman, M.; Cheruku, R.R.; Durrani, F.; Missert, J.R.; Watson, R.; Ohulchanskyy, R.Y.; Tracy, E.C.; Baumann, H.; Pandey, R.K. J. Med. Chem., 2016, 59, 9774-9787.

[121] Srivatsan, A.; Pera, P.; Joshi, P.; Wang, Y.; Missert, J.R.; Tracy, E.C.; Tabaczynski, W.A.; Yao, R.; Sajjad, M.; Baumann, H.; Pandey, R.K. Effect of chirality on cellular uptake, imaging and photodynamic therapy of 
photosensitizers derived from chlorophyll-a. Bioorg Med Chem., 2015, 23, 36033617.

[122] Yoon, I.; Li, J.Z.; Shim, Y.K. Advance in photosensitizers and light delivery for photodynamic therapy. Clin. Endosc., 2013, 46, 7-23.

[123] Jeon, Y.M.; Lee, H.S.; Jeong D.; Oh, H.K.; Ra, K.H.; Lee, M.Y.; Antimicrobial photodynamic therapy using chlorin $e_{6}$ with halogen light for acne bacteriainduced inflammation. Life Sci., 2015, 124, 56-63.

[124] Wohllebe, S.; Ulbrich, C.; Grimm, D.; Pietsch, J.; Erzinger, G.; Richter, R.; Häder, D-P. Photodynamic treatment of Chaoborus crystallinus larvae with chlorophyllin induces necrosis and apoptosis. Photochem. Photobiol., 2011, 87, $1113-1122$.

[125] Wohllebe, S. Bekämpfung von Parasiten in aquatischen Ökosystemen mittels natürlicher Photosensitizer. Ph.D. Thesis, University of Erlangen: Germany, 2010.

[126] Erzinger, G.S.; Souza, S.C.; Pinto, L.H.; Hoppe, R.; Del Ciampo, L.F.; Souza, O.; Correia, C.H.G.; Häder, D.P. Assessment of the impact of chlorophyll derivatives to control parasites in aquatic ecosystems. Ecotoxicology, 2015, 4, 949-954.

[127] Mahmoud, M.S.; Richter, P.; Shalaby, H.A.M.; Kandil, O.M.; Häder, D.P. Molluscicidal activity of chlorophyll extraction against the freshwater snails. $J$. Coast Life Med., 2013, 1, 85-88.

[128] Wohllebe, S.; Richter, R.; Richter, P.R.; Häder, D-P. Photodynamic control of human pathogenic parasites in aquatic ecosystems using chlorophyllin and pheophorbide as photodynamic substances. Parasitol Res., 2010, 10, 593-600.

[129] Abdel-Kader, M.H.; El-Tayeb, T.A. Field implementation using chlorophyll derivatives with sunlight for malaria, filaria and dengue fever vectors control in infested Africa swamps. Malaria J., 2012, 11, 42.

[130] Sarnoff, D.S. Therapeutic update on rosacea. J. Drugs Dermatol., 2014, 13, 1011.

[131] Vasili, D.B. Topical treatment with liposomal sodium copper chlorophyllin complex in subjects with facial redness and erythematotelangiectatic rosacea: case study. J. Drug Dermatol., 2015, 14, 1157-1159.

[132] Monya, L.S.; Stephens, T.J. Assesment of the safety and efficacy of topical copper chlorophyllin in women with photodamaged facial skin. J. Drugs Dermatol., 2015, 4, 401-404. 
[133] McCook, J.P.; Dorogi, P.L.; Vasily, D.B.; Cefalo, D.R. In vitro inhibition of hyaluronidase by sodium copper chlorophyllin complex and chlorophyllin analogs. Clin. Cosmet. Investig. Dermatol., 2015, 8, 443-448.

[134] Strompfová, V.; Kubašová, I.; Farbáková, J.; Gancarčíková, S.; Mudroňová, D.; Mad'ari, D.; Lauková, A. Experimental application of Lactobacillus fermentum CCM 7421 in combination with chlorophyllin in dogs. Appl. Microbiol. Biotechnol., 2015, 99, 8681-8690.

[135] Xu, C.; Zhang, J.; Mihai, D.M.; Washington, I. Light-harvesting chlorophyll pigments enable mammalian mitochondria to capture photonic energy and produce ATP. J. Cell Science, 2014, 127, 388-399.

[136] Zhang, D.; Robinson, K.; Mihai, D.M.; Washington, I. Sequestration of ubiquitous dietary derived pigments enables mitochondrial light sensing. Scientific Reports, 2016, 6, 34320-34333.

[137] Qu, J.; Ma, L.; Zhang, J.; Jockusch, S.; Washington, I. Dietary chlorophyll metabolites catalyze the photoreduction of plasma ubiquinone. Photochem. Photobiol., 2013, 89, 310-313.

[138] Johnsen, S. The red and the black: Bioluminiscence and the color of animals in the deep sea. Integr. Comp. Biol., 2005, 45, 234-246.

[139] Douglas, R.H.; Partridge, J.C.; Dulai, K.; Hunt, D.C.; Mullineaux, W.; Tauber, A.Y.; Hynninen, P.H. Dragon fish see using chlorophyll. Nature, 1998, 393, 423424.

[140] Washington, I.; Zhou, J.; Jockusch, S.; Turro, N.J.; Nakanishia, K.; Sparrow, J.R. Chlorophyll derivatives as visual pigments for super vision in the red. Photochem. Photobiol. Sci., 2007, 6, 775-779.

[141] Islam, M.T.; Barros de Alencar, M.V.O.; Machado, K.C.; Machado, K.C.; MeloCavalcante, A.A.C.; Sousa, D.P.; Mendes de Freitas, R. Phytol in a pharmamedico-stance. Chem. Biol. Interact., 2015, 240, 60-73.

[142] Van der Brink D.M.; Wanders, R.J. Phytanic acid: production from phytol, its breakdown and role in human disease. Cell Mol. Life Sci., 2006, 63, 1752-1765.

[143] Refsum, H.E. Acid-base status in patients with chronic hypercapnia and hypoxemia. Clin. Sci., 1964, 27, 407-410.

[144] Sjogren, T.; Larsson, T. Oligophrenia in combination with congenital ichthyosis and spastic disorders. Acta Psychiatr. Neurol. Scand., 1957, 32, 1-113. [145] Willemsen, M.A.; van Der Graaf, M.; van der Knaap, M.S.; Heerschap, A.; 
van Domburg, P.H.; Gabreels, F.J.; Rotteveel, J.J. MR imaging and proton MR spectroscopic studies in Sjögren-Larsson syndrome: characterization of the leukoencephalopathy. AJNR Am. J. Neuroradiol., 2004, 25, 649-657.

[146] Kitareewan, S.; Burka, L.T.; Tomer, K.B.; Parker, C.E.; Deterding, L.J.; Stevens, R.D.; Forman, B.M.; Mais, D.E.; Heyman, R.A.; McMorris, T.; Weiberger, C. Phytol metabolites are circulating dietary factors that activate the nuclear receptor RXR, Mol. Biol. Cell, 1996, 7, 1153-1166.

[147] Schluter, A.; Barbera, M.J.; Iglesias, R.; Giralt, M.; Villarroya, F. Phytanic acid, a novel activator of uncoupling protein-1 gene transcription and brown adipocyte differentiation, Biochem. J. 2002, 362, 61-69.

[148] Ellinghaus, P.; Wolfrum, C.; Assmann, G.; Spener, F.; Seedorf, U. Phytanic acid activates the peroxisome proliferator-activated receptor $\alpha(\operatorname{PPAR} \alpha)$ in sterol carrier protein 2-/sterol carrier protein x-deficient mice. J. Biol. Chem., 1999, 274, 2766-2772.

[149] Goto, T.; Takahashi, N.; Kato, S.; Egawa, K.; Ebisu, S.; Moriyama, T.; Fushiki, T.; Kawada, T. Phytol directly activates peroxisome proliferator-activated receptor a (PPARa) and regulates gene expression involved in lipid metabolism in PPARa-expressing HepG2 hepatocytes. Biochem. Biophys. Res. Commun., 2005, $337,440-445$. 


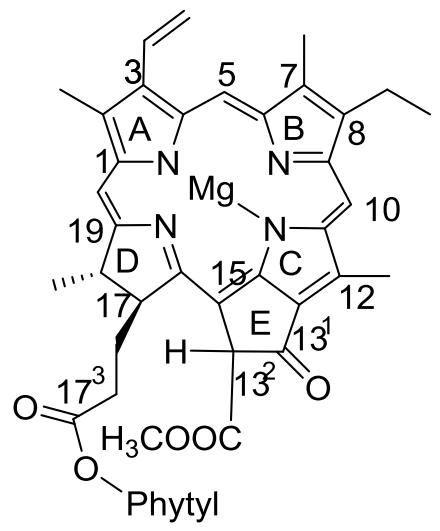

Chlorophyll a (1) 


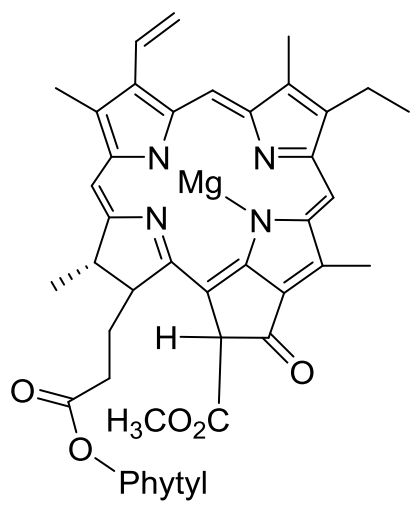

Chlorophyll a (1)

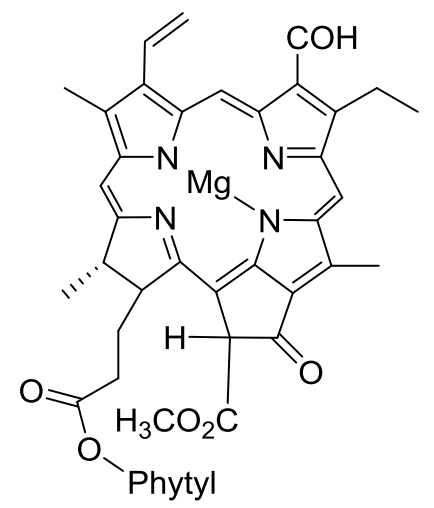

Chlorophyll $b$ (2)

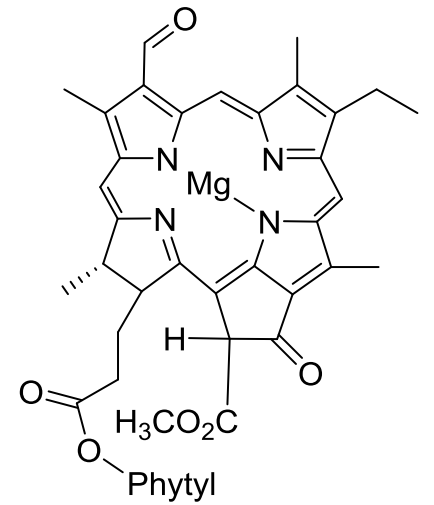

Chlorophyll $d(3)$

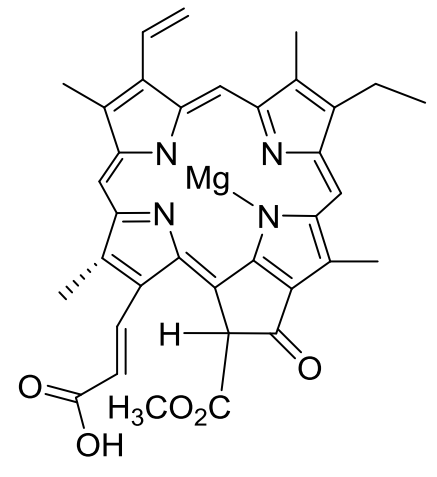

Chlorophyll $c_{1}(4)$

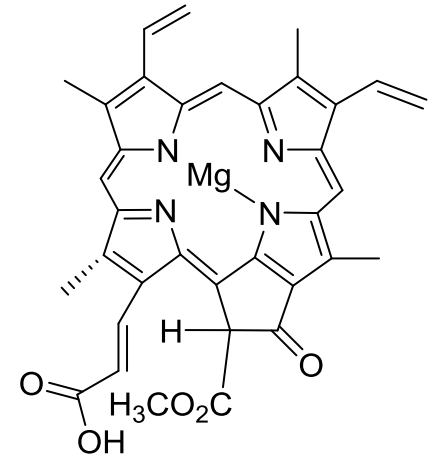

Chlorophyll $c_{2}(\mathbf{5})$ 


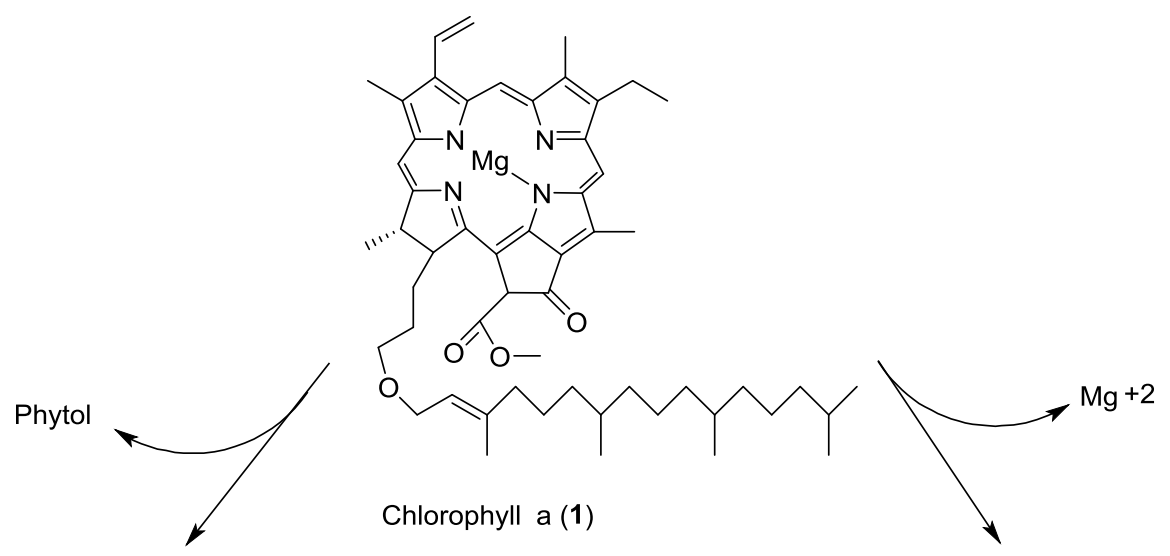

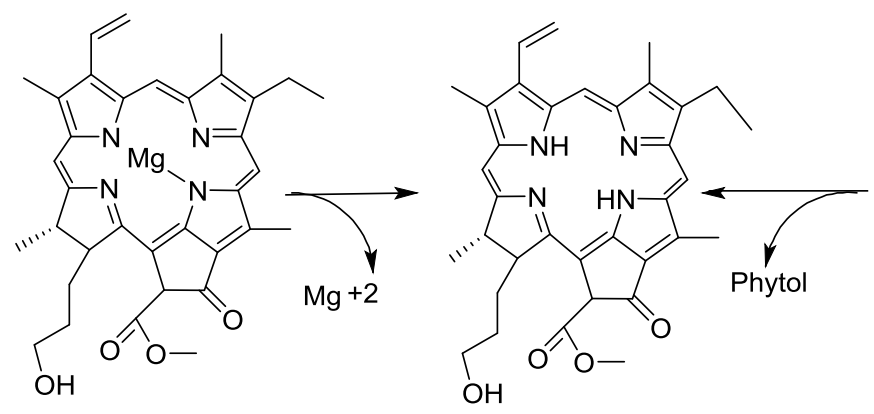

Chlorophyllide a (8)

Pheophorbide a (7)

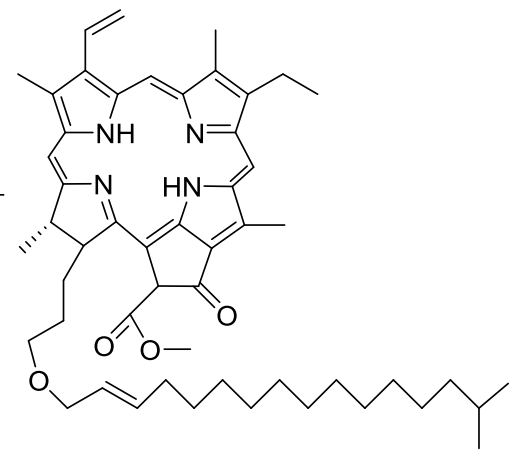

Pheophytin a (6)

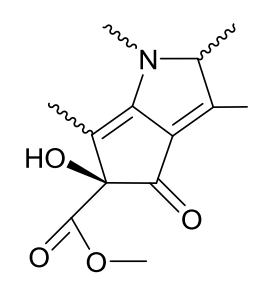

$132 \mathrm{OH}$-derivatives (9)

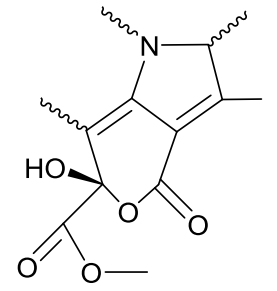

151-OH-lactone-derivatives (10)

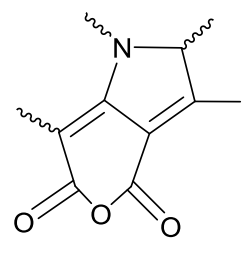

purpurin 18 (11)

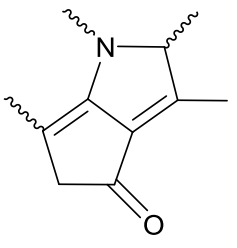

-derivatives

(12) 


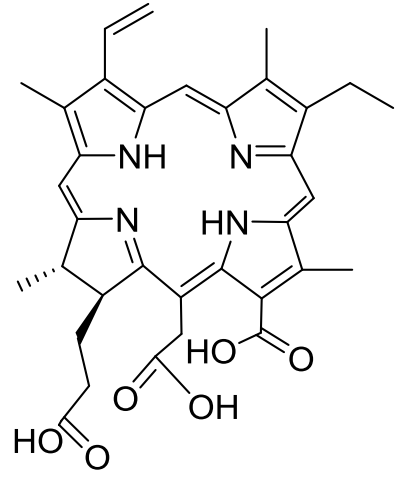

Chlorin $e_{6}(13)$

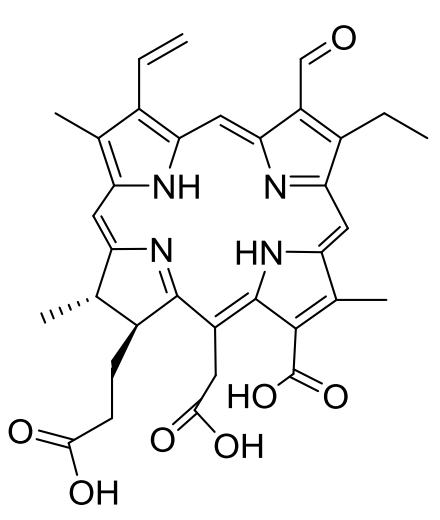

Rhodin $g_{7}$ (14) 


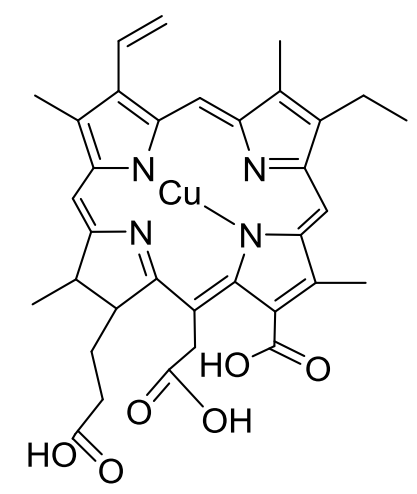

Cu-chlorin $e_{6}(15)$

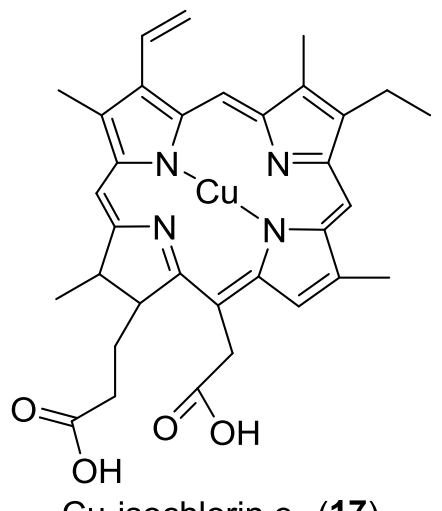

Cu-isochlorin $\mathrm{e}_{4}(17)$

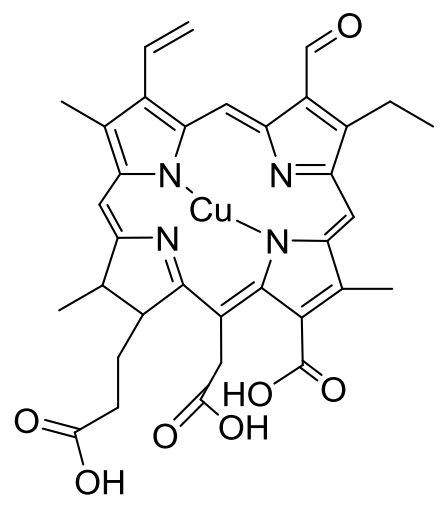

Cu-rhodin $g_{7}$ (19)<smiles></smiles>

Cu-rhodochlorin (21)

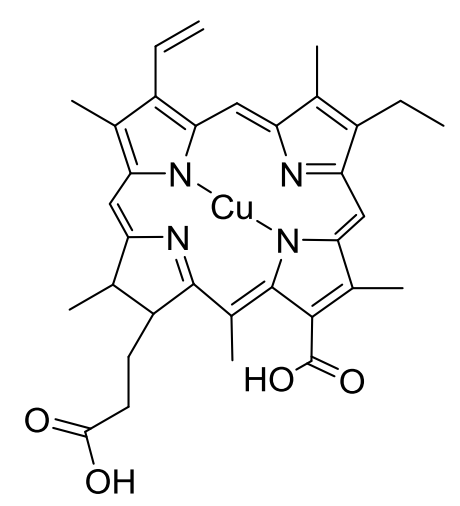

Cu-chlorin $e_{4}(16)$

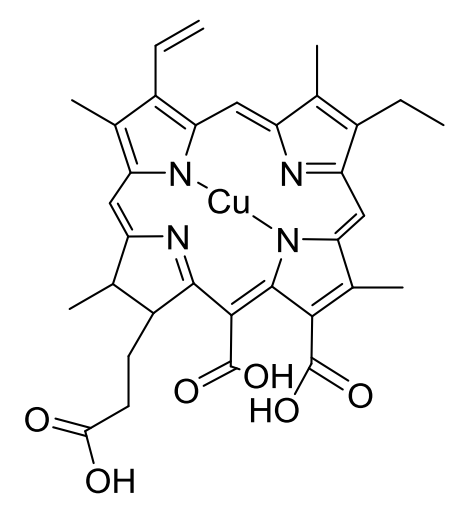

Cu-chlorin $p_{6}$ (18)

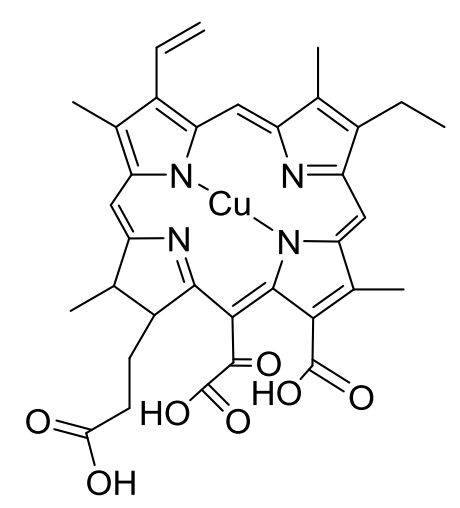

Cu-purpurin 7 (20) 


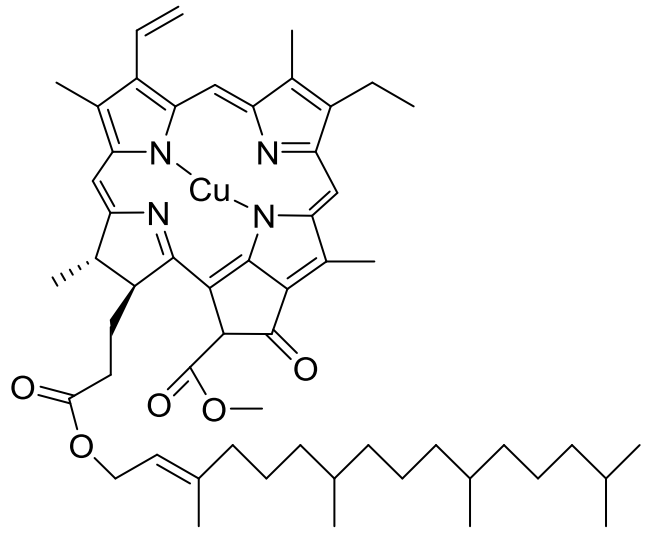

Cu-pheophytin (22)

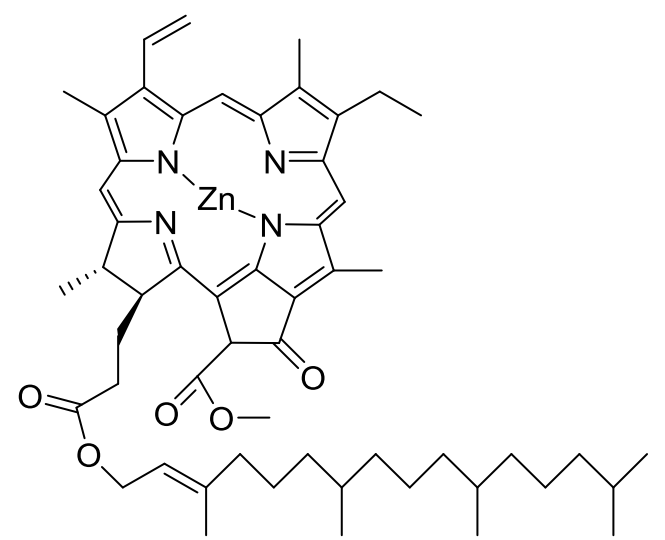

Zn-pheophytin (23) 


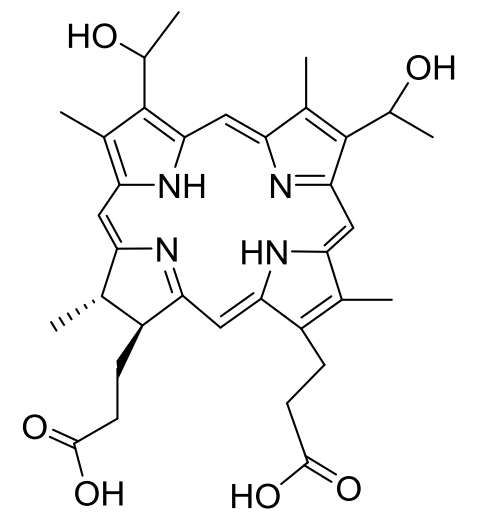

Hematoporphyrin (24)

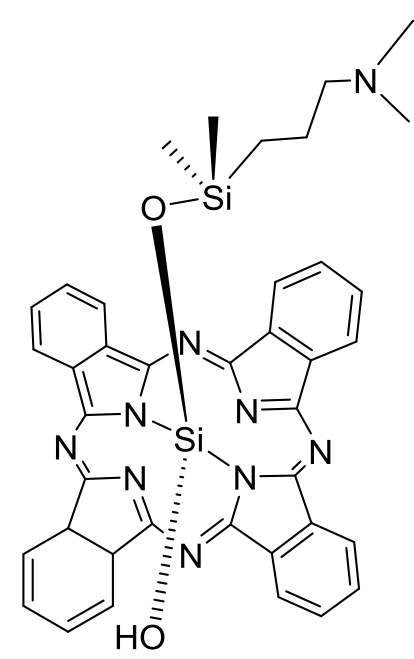

Pc4 (26)

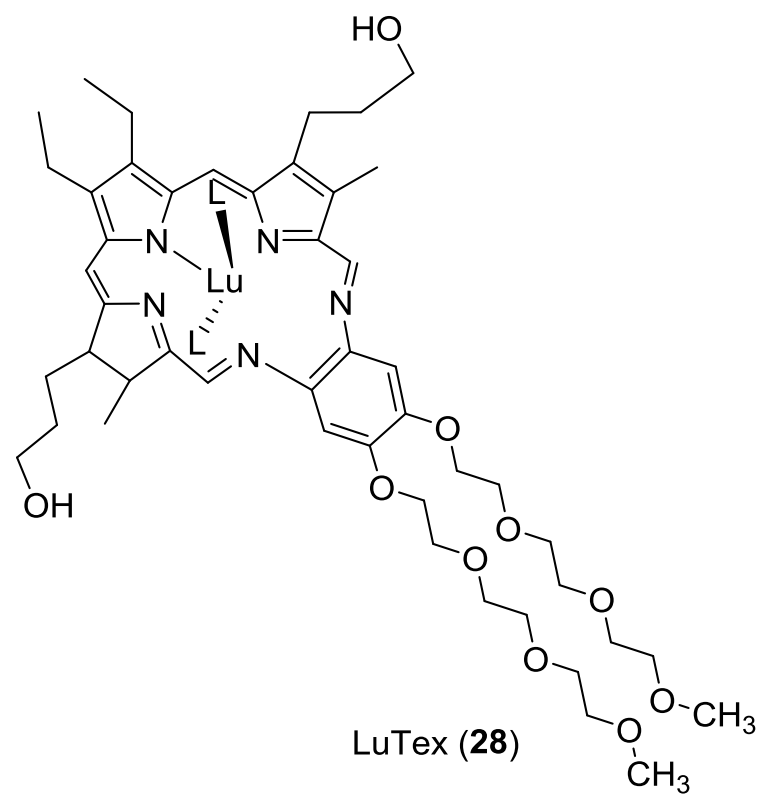

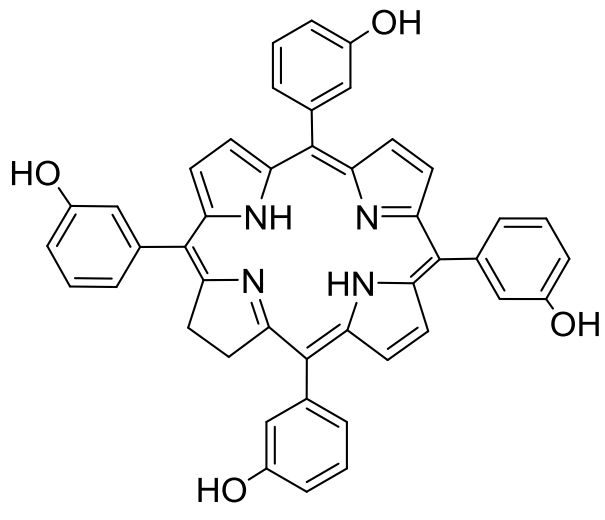

m-THPP (25)

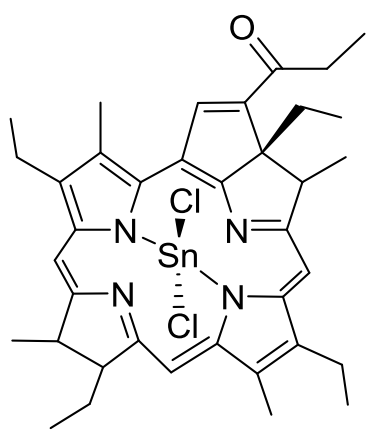

$\mathrm{SnT}_{2}(27)$

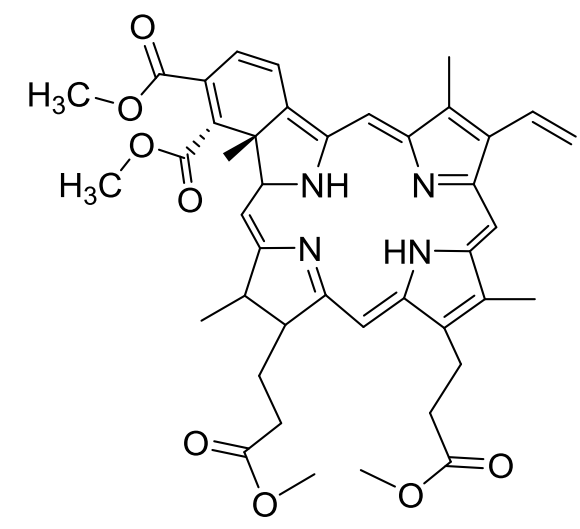

Veteporfin (29) 


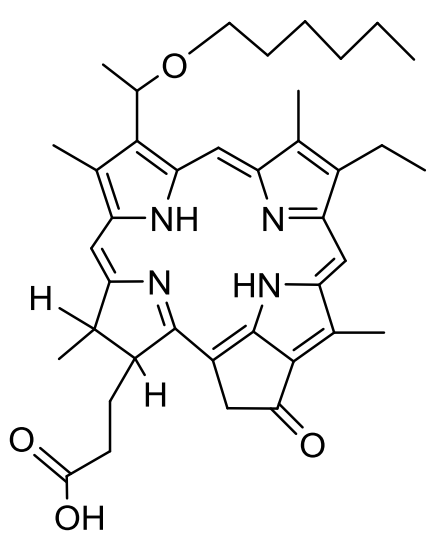

HPPH (31)

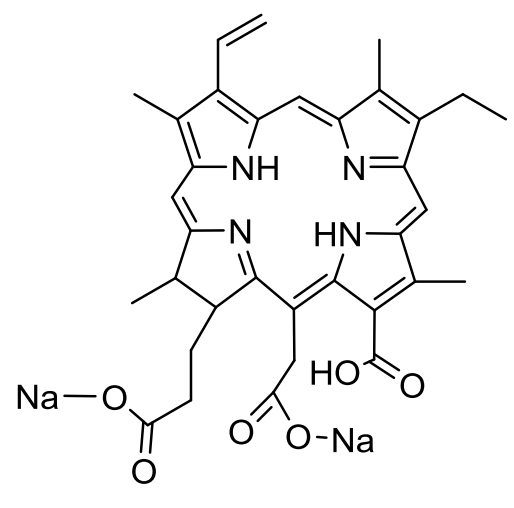

Sodium chlorin $e_{6}(\mathbf{3 3})$

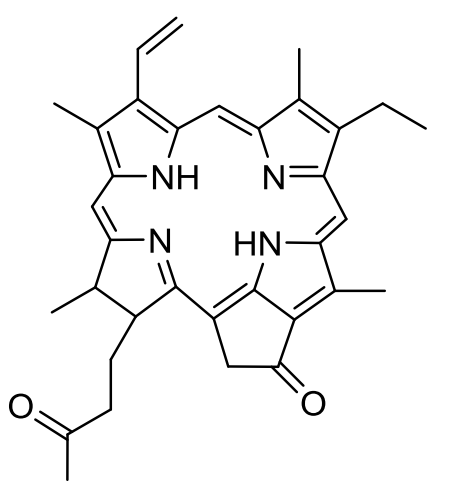

Methyl pyropheophorbide a (35)

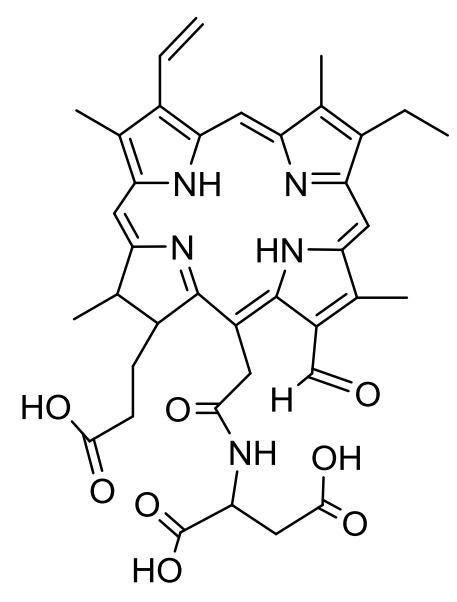

$\mathrm{NPe}_{6}(32)$

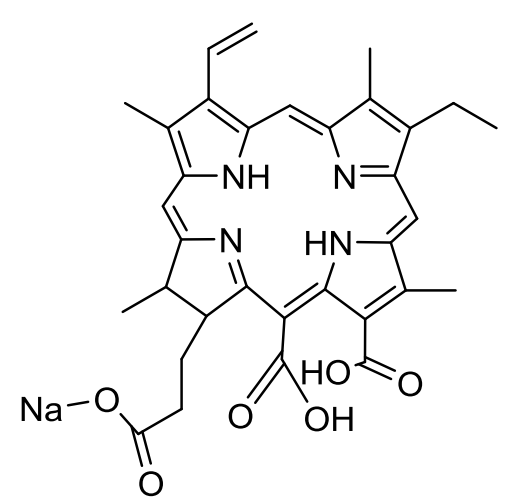

Sodium chlorin $p_{6}(\mathbf{3 4})$

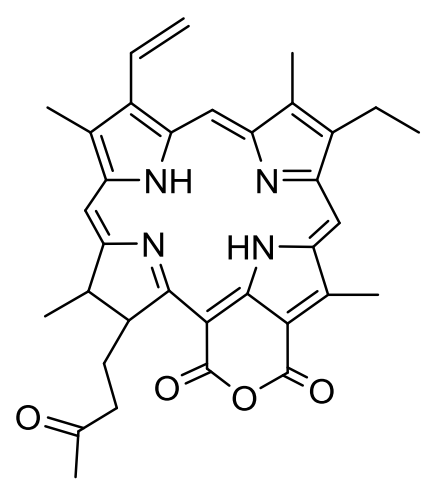

Purpurin-18 methyl ester (36) 


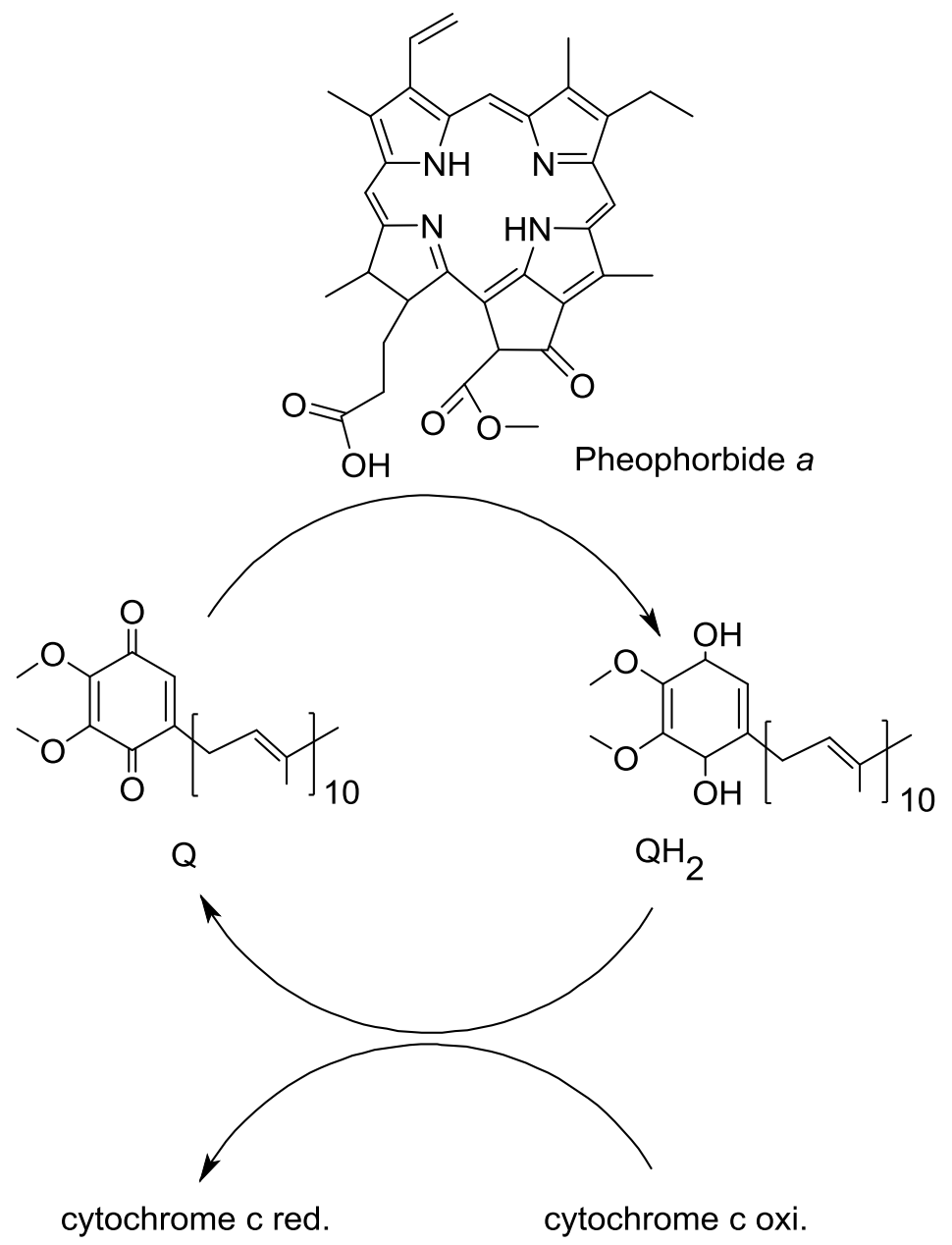




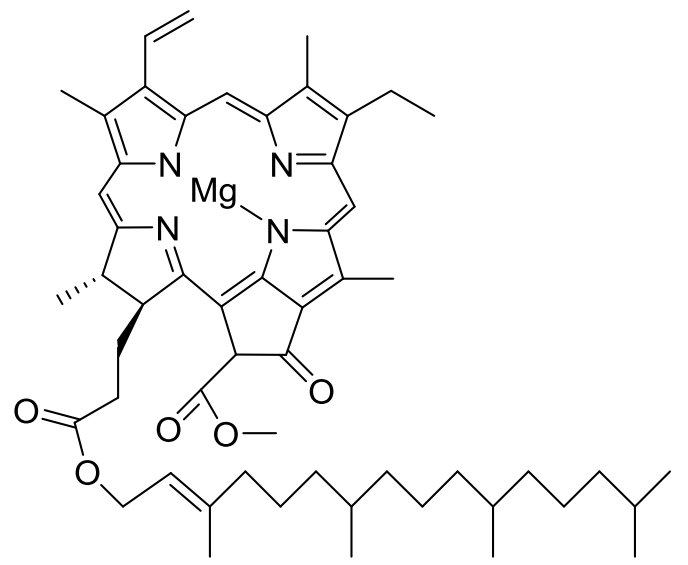

Chlorophyll a (1)

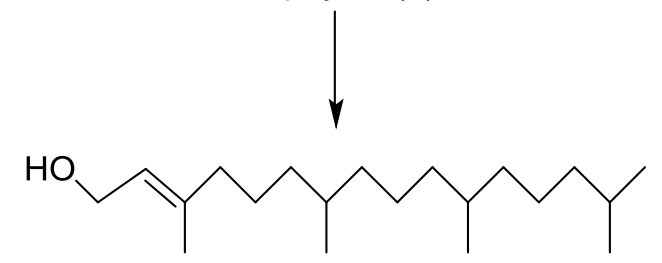

Phytol<smiles>C/C(=C\C(=O)O)CCCC(C)CCCC(C)CCCC(C)C</smiles>

Acid phytenic

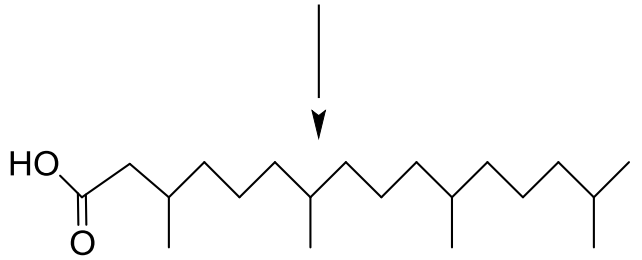

Acid phytanic

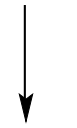<smiles>CC(C)CCCC(C)CCCC(C)CCCC(C)C(=O)O</smiles>

Acid pristanic 